\title{
Summertime Surface Wind Variability over Northeastern North America at Multidecadal to Centennial Time Scales via Statistical Downscaling
}

\author{
Etor E. Lucio-EceizA AND J. Fidel GonZÁleZ-Rouco \\ Facultad de Ciencias Físicas, Universidad Complutense Madrid, and Instituto de Geociencias (UCM-CSIC), Madrid, Spain \\ ElENA GARCÍA-BustamANTE AND JORGE NAVARro \\ División de Energías Renovables, Centro de Investigaciones Energéticas, Medioambientales y Tecnológicas (CIEMAT), \\ Madrid, Spain \\ CRISTINA ROJAS-LABANDA \\ Facultad de Ciencias Físicas, Universidad Complutense Madrid, and Instituto de Geociencias (UCM-CSIC), Madrid, Spain \\ Hugo BeLTRAMI \\ Climate and Atmospheric Sciences Institute, St. Francis Xavier University, Antigonish, Nova Scotia, Canada
}

(Manuscript received 13 May 2019, in final form 18 October 2019)

\begin{abstract}
The variability of the surface zonal and meridional wind components over northeastern North America during June-October is analyzed through a statistical downscaling (SD) approach that relates the main wind and large-scale circulation modes. An observational surface wind dataset of 525 sites over 1953-2010 provides the local information. Twelve global reanalyses provide the large-scale information. The large-to-local variability of the wind field can be explained, to a large extent, in terms of four coupled modes of circulation explaining a similar amount of variance. The SD method is mostly sensitive to the number of retained modes and subregionally to the large-scale information variable, but not to the reanalysis source. The SD methodological uncertainty based on the use of multiple configurations is directly related to the variability of the wind, similar in relative terms for both components. With an adequate choice of parameters the SD estimates provide more realistic variances than the reanalysis wind, although their correlations with respect to observations are lower than the latter. Additionally, while these different SD estimations are very similar on the reanalysis used, the various reanalysis wind fields show noticeable differences, especially in their variances. The wind variability is reconstructed back to 1850 , making use of century-long reanalyses and two additional SLP gridded datasets, which allows estimating the variability at decadal to multidecadal time scales. Recent negative (significant) trends in the zonal component do not stand out in the multidecadal context, but they are consistent with a global stilling process, and are partially attributable to changes in the large-scale dynamics.
\end{abstract}

\section{Introduction}

Surface wind is a meteorological variable that affects society in multiple aspects, from its effects in agriculture (Farquhar and Roderick 2005; McVicar et al. 2012) to the risk of damage on facilities (Khanduri and Morrow 2003), as wind energy resource gains relevance (Murthy and Rahi 2017). Surface wind studies encompass analyses at many different time scales, from hourly (Tuller 2004; Sharp et al. 2015) and daily evolution (Yan et al. 2002; Brinckmann et al. 2016) to its long-term past

Corresponding author: Etor E. Lucio-Eceiza, eelucio@fis.ucm.es
(Pryor et al. 2009; García-Bustamante et al. 2012), present (Klink 1999; McVicar et al. 2008), or future (Najac et al. 2009; Pryor et al. 2012b) variability. Some emphasis has been given to extreme events (Smits et al. 2005; Cheng 2014) and linear trends (Vautard et al. 2010; McVicar et al. 2012; Azorin-Molina et al. 2014), and there is a growing interest in wind power assessment studies (Troen and Petersen 1989; García-Bustamante et al. 2013; Correia et al. 2017).

Surface wind is largely shaped by the general circulation of the atmosphere in interaction with the regional/ local orographic and thermodynamic characteristics of the surroundings (e.g., Atkinson 1981; Bianco et al. 
2006). Over northeastern North America, this circulation system is primarily related to pressure gradients that, on average, are characterized by semipermanent high pressure cells over the subtropics and poles, interspaced by the Icelandic and Aleutian lows (Peixoto and Oort 1992). This large-scale configuration experiences a seasonal variation with intensified low pressure systems over high latitudes that drive intense and mostly zonal flows from the west during wintertime, and a slight displacement toward the pole of subtropical highs that produce weaker and more meridional (west/southwest) winds during summer. Summer is also characterized by a smaller variance of the wind field (Klink 1999) attributable on one hand to the aforementioned lower average wind speeds but also to the fewer and weaker very high wind episodes during these months (Lucio-Eceiza et al. 2019). The weakening of very high wind episodes is partially related to less intense and scarcer cyclone and anticyclone passages during summer (Wang et al. 2006). These cyclones mainly originate from either convective storms (thunderstorms and tornadoes) that occur mostly inland, or from storms of tropical origin like hurricanes (Richards and Abuamer 2007) that can also transition to extratropical cyclones (Hart and Evans 2001). Previous analyses of the recent past and future wind variations over the conterminous United States (e.g., Klink 1999; Pryor et al. 2012a) and Canada (e.g., Wan et al. 2010; Martinez et al. 2013) can be found in the literature. However, this is the first attempt to describe the longterm (multidecadal to centennial) past wind behavior and associated trends over the region of northeastern North America, combining both wind observations and estimates. These wind estimations are directly and indirectly obtained from all the current global reanalysis datasets, and include a thorough uncertainty analysis. The analysis in the current work is centered during the extended warm season encompassing the months of June-October (JJASO; referred to simply as summer/summertime for shortening hereafter), complementing a similar analysis conducted by Lucio-Eceiza et al. (2019), that targeted the extended cold season (November-March).

This analysis has been conducted through a statistical downscaling (SD) method mainly based on empirical orthogonal functions (EOFs) and canonical correlation analysis (CCA; e.g., García-Bustamante et al. 2012). The purpose of this SD methodology is twofold. On one side it identifies the main circulation patterns (CCA patterns) governing the flow over the region and their associated time evolution (canonical series or CS). On the other side, the methodology offers the possibility to estimate the local wind, hence the downscaling aspect of the technique. These estimates, however, need to be taken with care as they are subject to uncertainties, some of which are related to the methodology applied (e.g., Huth 2002; Fowler et al. 2007; Najac et al. 2009; GarcíaBustamante et al. 2012; Themeß1 et al. 2011; Culver and Monahan 2013; Wu et al. 2017). Additionally, and as long as we assume that the statistical relationships that have been established are valid in the past (von Storch et al. 1993), the time series can be extended back in time as far as large-scale information is available, to enable the reconstruction of the wind behavior for time periods beyond that of the observational set.

This work describes in detail the main governing large-scale patterns over the region during summer, linking them to the best-known circulation modes in the area with the help of several teleconnection indices. The estimations of the local wind based on the obtained large-tolocal scale relationships are provided. It also describes the long-term variability of the large-to-local coupled patterns, showing the multidecadal to centennial behavior of the reconstructed regional wind with the help of twentieth century reanalyses and historical databases. Additionally, it also offers a sensitivity analysis of the SD applied to several methodological aspects. The work places an emphasis on analyzing the sensitivity to selecting any of the existing 12 global reanalyses and two additional observational gridded datasets as large-scale information sources. Such an exercise, to our knowledge, has not yet been done.

Section 2 describes the observational database, the large-scale circulation variable fields, and the teleconnection indices used in the analysis, while section 3 describes the methodological and experimental setup for the SD estimates and uncertainty evaluation. Section 4 presents the main large-to-local-scale coupled modes of circulation that govern the wind variability over this region using a particular initial configuration of the SD model as basis. Section 5 explores the sensitivity of the SD wind estimations to changes of SD methodological aspects. The SD estimates using a skillful configuration is also conducted, in comparison with the wind field simulated from the different reanalyses. A past estimation and its associated uncertainty of the wind variability is presented in section 6, covering the $1850-2010$ period and using two observational gridded datasets as largescale information in addition to the reanalyses. Finally, section 7 discusses the main findings of this work in the context of the wintertime climatological variability described in Lucio-Eceiza et al. (2019).

\section{Data}

\section{a. Observational wind data}

Our region of interest is centered in northeastern North America, for which an observational surface wind speed and direction database was previously compiled 

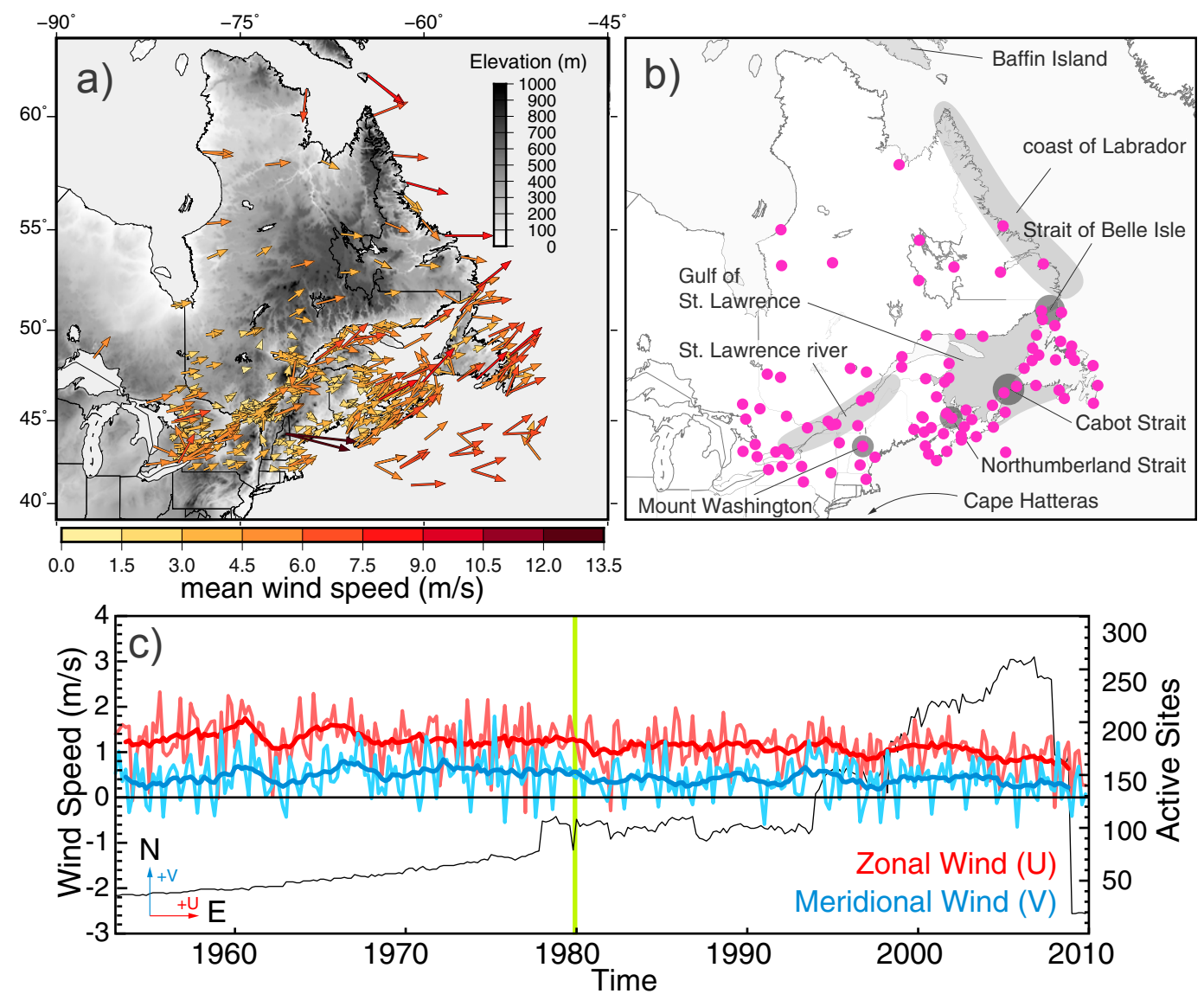

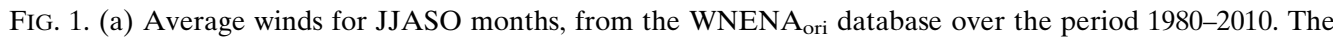
wind speed is given by the color code and length of the arrow. The topography is given in grayscale. (b) Spatial distribution of the 95 selected sites for the statistical downscaling process $\left(W_{N E N A}\right.$ ). Some of the more noteworthy geographical features of the region have been highlighted in the map. (c) Regional mean (left $y$ axis) of

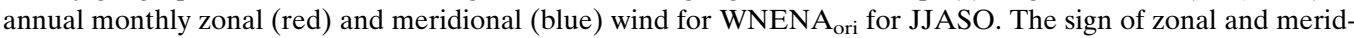
ional components respect to the compass are indicated in the inlet. The thicker lines correspond to a 10-month centered running mean (i.e., 2 -yr low pass filter). The number of active sites at any month is indicated with the black line (right $y$ axis). The beginning of the training period (1980-2010) is highlighted.

and quality controlled in Lucio-Eceiza et al. (2018a,b). This surface wind database over northeastern North America (from now on WNENA ori $_{\text {; }}$ Fig. 1a) consists of 525 sites of hourly, 3-hourly, and 6-hourly records that span almost 60 years from 1953 to 2010, although for this work we have used monthly averages. The summertime mean wind variability is characterized by westerly winds with a marked southwesterly component over the southern areas. These winds reach maximum average values of up to $9 \mathrm{~m} \mathrm{~s}^{-1}$ along the coast of Labrador, the eastern side of Newfoundland and Nova Scotia, and at the mouth of St. Lawrence River (some of the most important geographical features of this region are highlighted in Fig. $1 \mathrm{~b}$ as they are mentioned in the description of the CCA patterns of section 4). One of the most evident orographic effects on the surface wind over this region is the wind channeling along the St. Lawrence River and the straits of Belle Isle, Cabot, and Northumberland, and on the particularly high mean winds at the top of Mt. Washington (New Hampshire, $1917 \mathrm{~m}$ MSL, with winds of up to $13 \mathrm{~m} \mathrm{~s}^{-1}$ ). Following Lucio-Eceiza et al. (2019), in this SD exercise we will use the zonal and meridional wind components.

Figure 1c shows the regional average of the zonal and meridional wind components for the extended JJASO summer season from $\mathrm{WNENA}_{\text {ori }}$. Although the regional zonal winds are overall more intense than the meridional ones throughout the whole observational period, the meridional component is large enough to meaningfully contribute with the westerly/southwesterly flow. Both components show a marked variability at intra-annual and annual scales, which is also apparent at lower $(2-4 \mathrm{yr})$ 
TABLE 1. Characteristics of the large-scale variables: variables used, data source, height, and units.

\begin{tabular}{llcc}
\hline \multicolumn{1}{c}{ Variable } & \multicolumn{1}{c}{ Source } & Level & Units \\
\hline Mean sea level pressure (SLP) & Observations/reanalysis & Surface pressure reduced to sea level & $\mathrm{hPa}$ \\
Zonal $(U)$ wind component & Reanalysis & $10 \mathrm{~m}$ & $\mathrm{~m} \mathrm{~s}{ }^{-1}$ \\
Meridional $(V)$ wind component & Reanalysis & $10 \mathrm{~m}$ & $\mathrm{~m} \mathrm{~s}$ \\
Geopotential height $(Z)$ & Reanalysis & $850,500 \mathrm{hPa}$ & $\mathrm{m}$ \\
Thermal thickness $(\Delta Z)$ & Reanalysis & $\Delta Z=Z_{500}-Z_{850}$ & $\mathrm{~m}$ \\
\hline
\end{tabular}

frequencies (not shown). The variance during the first decades is larger, although it could be an artifact of the relatively fewer number of sites providing observational data (i.e., active sites) before late 1970s (see black line in Fig. 1c). The overall summertime long-term linear trend for regional zonal winds is statistically significant $(p<0.05)$ albeit small (around $-0.09 \mathrm{~m} \mathrm{~s}^{-1}$ decade $^{-1}$ ), intensifying during the last $1980-2010$ period $\left(-0.11 \mathrm{~m} \mathrm{~s}^{-1}\right.$ decade $\left.^{-1}\right)$. The sign of these trends is in accordance with the stilling of wind speed recorded worldwide and particularly at the Northern Hemisphere (e.g., Vautard et al. 2010; McVicar et al. 2012).

In view of the uneven number of WNENA ori $_{\text {active }}$ sites through the whole observational period, we have reduced the number of sites involved in the downscaling exercise to avoid a large proportion of missing values in the records that can generate instabilities in the EOF methodologies (e.g., Jiménez et al. 2008). To ensure the spatial and temporal homogeneity of our subset, we have narrowed down our period of analysis to 1980-2010 (henceforth the training period) and constructed the subset (WNENA ${ }_{S D}$, see Fig. 1b) based on 95 sites with at least $50 \%$ of valid data during this training period.

\section{b. Large-scale variables}

Following Lucio-Eceiza et al. (2019), we have selected six different variables for the large-scale information (Table 1): 10-m height meridional $(U)$ and zonal $(V)$ wind components, sea level pressure (SLP), 850- and 500-hPa geopotential height $\left(Z_{850}\right.$ and $\left.Z_{500}\right)$, and 500850-hPa thickness $(\Delta Z)$. SLP gradients drive the surface wind (van der Kamp et al. 2012), while the choice of geopotential heights and thickness is based on the results of previous works that showed potential predictability of surface winds from the dynamical and thermal description of the flow aloft (e.g., García-Bustamante et al. 2012; Monahan 2012). The variables, all in monthly resolution, have been obtained from the 12 global reanalysis products available up to date; additionally, for SLP two observational gridded databases have also been used (see Table 2).

All reanalyses cover approximately the 1980-2010 training period and half of them span the whole observational period (1950s). Three reanalyses (ERA-20C,
CERA-20C, and 20CRv2c, hereafter referred to collectively as twentieth century reanalyses) and the two SLP instrumental datasets cover the whole twentieth century, even going back to the mid-nineteenth century in some cases. The vast majority of the reanalyses are purely atmospheric models, and while there is a wide range of assimilated variable types, none of the reanalyses assimilate surface wind from land sites (Uppala et al. 2005; Onogi et al. 2007; Dee et al. 2011; Ebita et al. 2011; Rienecker et al. 2011; Kobayashi et al. 2014; D. Schuster 2016, personal communication), thus assuring statistical independence with WNENA $\mathrm{SD}_{\mathrm{SD}}$. In the cases of CERA-20C and 20CRv2c, which comprise ensembles of 10 and 56 members, respectively, only the ensemble mean has been used. For a more extensive description of the reanalysis products and gridded datasets the reader is referred to Table 2 and Lucio-Eceiza et al. (2019).

\section{c. Large-scale circulation indices}

The CSs resulting from the applied SD methodology have been correlated with 10 teleconnection indices relevant in both the Pacific and Atlantic basins (Table 3) in order to relate regional patterns found in the SD analysis with well-known circulation modes.

\section{Statistical downscaling methodology}

The analyses in this work have been conducted through a downscaling approach that looks for statistical relationships between large-scale atmospheric circulation patterns (predictors) and the local surface wind (predictands). Our SD methodology is mainly based on EOFs and CCAs, two multivariate statistical techniques similar in objectives and mathematics (Pearson 1901; Lorenz 1956). These techniques are especially well suited to capture spatial patterns with homogeneously behaving subregions, and allowing for the physical interpretation of the links between large-to-local circulations (Zorita and von Storch 1999; Huth 2002). This methodology has been applied before to variables such as precipitation (e.g., González-Rouco et al. 2000; Hertig et al. 2012) and temperature (e.g., Xoplaki et al. 2003; Wójcik 2015), and less frequently with wind-related 


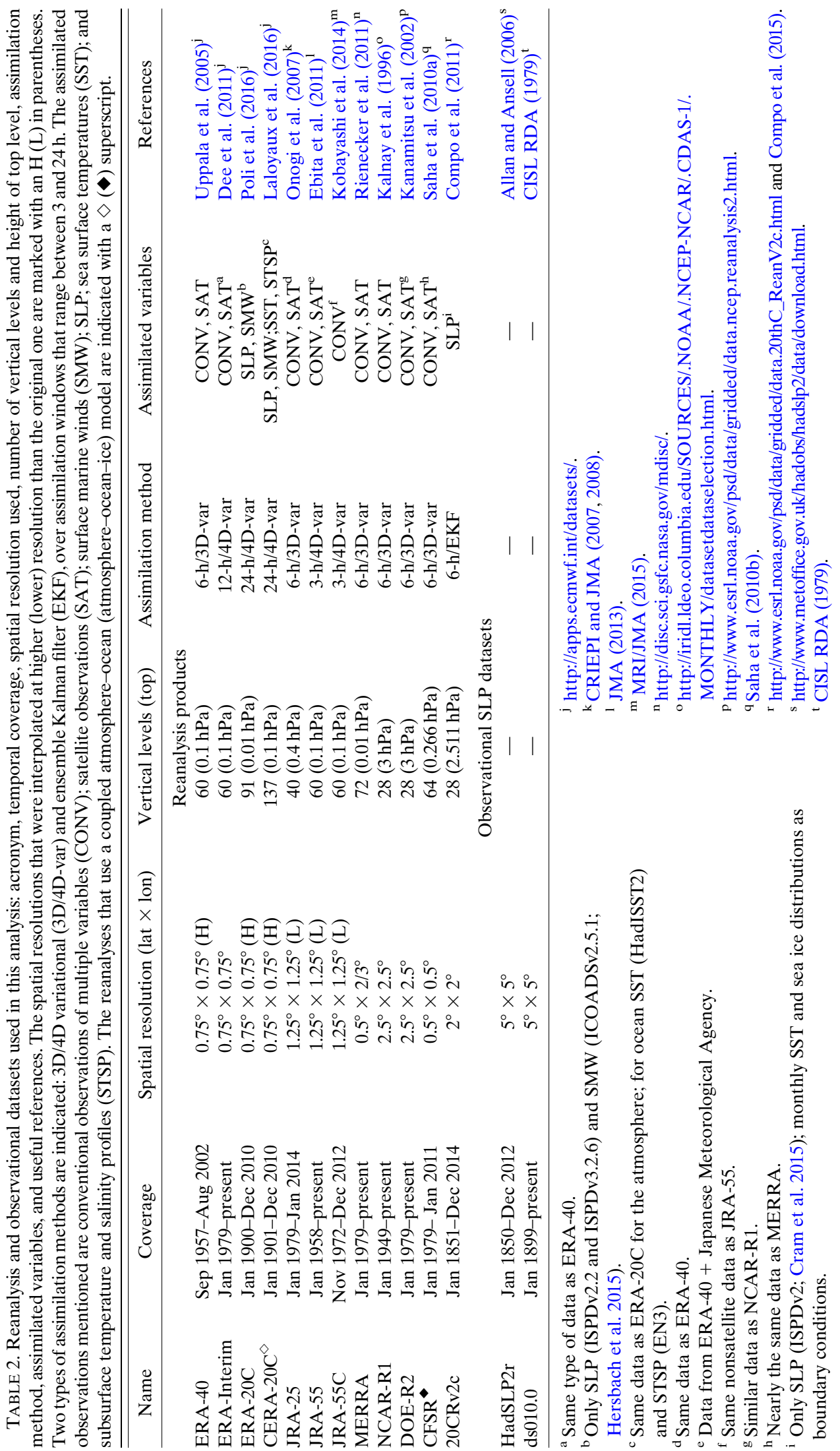


TABLE 3. Description of the teleconnection indices: name, atmospheric variable on which the index is based, short description, and useful references. NH stands for Northern Hemisphere, PC for principal component, and RPCA for rotated principal component analysis. This table can also be found in Lucio-Eceiza et al. (2019).

\begin{tabular}{|c|c|c|c|c|}
\hline Index & Name & Variable & Description & Reference \\
\hline AO (NAM) & $\begin{array}{l}\text { Arctic Oscillation (northern } \\
\text { annular mode) }\end{array}$ & SLP & $\begin{array}{l}1979-2000 \text { monthly PC1 at } \\
1000 \mathrm{hPa}>20^{\circ} \mathrm{N}\end{array}$ & $\begin{array}{l}\text { Thompson and Wallace }(1998, \\
2000 \mathrm{a}, \mathrm{b})^{\mathrm{a}}\end{array}$ \\
\hline NAO & North Atlantic Oscillation & SLP & $\begin{array}{l}1899-2014 \mathrm{PC} 1 \text { over }\left(20^{\circ}-80^{\circ} \mathrm{N},\right. \\
\left.90^{\circ} \mathrm{W}-40^{\circ} \mathrm{E}\right)\end{array}$ & Hurrell $(1995)^{\mathrm{b}}$ \\
\hline EA & East Atlantic & $Z_{500}$ & $\begin{array}{l}\text { 1981-2000 standardized RPCA } \\
\text { over NH }\end{array}$ & Barnston and Livezey $(1987)^{\mathrm{c}}$ \\
\hline EA/WR & Eastern Asia/Western Russia & $Z_{500}$ & $\begin{array}{l}\text { 1981-2000 standardized RPCA } \\
\text { over NH }\end{array}$ & Barnston and Livezey $(1987)^{\mathrm{a}}$ \\
\hline SCAND & Scandinavian Pattern & $Z_{500}$ & $\begin{array}{l}\text { 1981-2000 standardized RPCA } \\
\text { over NH }\end{array}$ & Barnston and Livezey $(1987)^{\mathrm{c}}$ \\
\hline NP & North Pacific & SLP & $\begin{array}{l}\text { Area-weighted over }\left(30^{\circ} \mathrm{N}-65^{\circ} \mathrm{N},\right. \\
\left.160^{\circ} \mathrm{E}-140^{\circ} \mathrm{W}\right)\end{array}$ & Trenberth and Hurrell (1994), ${ }^{\mathrm{a}}$ \\
\hline PNA & Pacific North American Oscillation & $Z_{500}$ & $\begin{array}{l}\text { 1981-2000 standardized RPCA } \\
\text { over NH }\end{array}$ & Barnston and Livezey $(1987)^{\mathrm{a}}$ \\
\hline $\begin{array}{l}\text { ENSO } \\
\qquad \text { (Niño 3) }\end{array}$ & El Niño-Southern Oscillation & SST & $\begin{array}{l}1981-2010 \text { anomalies over }\left(5^{\circ} \mathrm{N}-\right. \\
\left.5^{\circ} \mathrm{S}, 150^{\circ}-90^{\circ} \mathrm{W}\right)\end{array}$ & $\begin{array}{l}\text { Rasmusson and Wallace (1983); } \\
\text { Cane }(1986)^{\mathrm{a}}\end{array}$ \\
\hline SOI & Southern Oscillation index & SLP & $\begin{array}{l}\text { Tahiti minus Darwin standardized } \\
\text { over 1981-2010 }\end{array}$ & $\begin{array}{l}\text { Trenberth (1984); Ropelewski and } \\
\text { Jones (1987), }{ }^{\mathrm{a}}\end{array}$ \\
\hline PDO & Pacific decadal oscillation & SST & $\begin{array}{l}\text { PC1 of monthly anomalies in North } \\
\text { Pacific Ocean }\end{array}$ & $\begin{array}{l}\text { Mantua et al. (1997); Yuan Zhang } \\
\text { et al. (1997), }{ }^{\text {a }}\end{array}$ \\
\hline
\end{tabular}

${ }^{a}$ Downloaded from ESRL-NOAA Climate Indices List (http://www.esrl.noaa.gov/psd/data/climateindices/list/).

${ }^{\mathrm{b}}$ Downloaded from NCAR-UCAR Climate Data Guide (https://climatedataguide.ucar.edu/climate-data/hurrell-north-atlantic-oscillationnao-index-pc-based; National Center for Atmospheric Research 2016).

${ }^{\mathrm{c}}$ Downloaded from CPC/NCEP-NOAA list (http://www.cpc.ncep.noaa.gov/data/teledoc/telecontents.shtml).

variables (Kaas et al. 1996; García-Bustamante et al. 2012, 2013; Lucio-Eceiza et al. 2019) as well.

This SD method uses anomaly fields of both predictand and predictor variables that are treated prior to their use in the SD method. The anomaly fields are detrended to avoid inflated correlation values attributable to long-term trends (Xoplaki et al. 2004), and normalized to avoid the instabilities produced by disparate variance values at different site/grid points (GarcíaBustamante et al. 2012). Additionally, the predictor fields are also weighted to compensate for latitudinal distortions (North et al. 1982). A more detailed account of this process can be found in Lucio-Eceiza et al. (2019). The local wind estimates are conducted using a regression model that presents the predictand variables as linear combinations of the CCA patterns and the predictor fields. Since the anomaly fields of both predictor and predictand were detrended, both the CSs and estimations shown in sections 4 and 5 are therefore also detrended. The reconstruction exercise in section 6 is, however, conducted using nondetrended predictor fields.

Initially, a specific combination of model parameters is selected (section 4), chosen to illustrate the major associations between predictor and predictand fields. Taking this initial configuration as reference (reference configuration hereafter), an evaluation of the sensitivity of the estimates to changes in five different methodological choices is then conducted (section 5a). These parameters are 1) the size of the large-scale domain or window size for the predictor; 2 ) the variable(s) used as predictor field; 3) the number of retained circulation patterns $(\mathrm{EOF} /$ CCA modes); 4) the robustness of the method to possible data overfitting given by the size of the cross-validation subset; and 5) the source of the predictor variables.

Following Lucio-Eceiza et al. (2019) five possible domains are chosen for the window size: A $\left(35^{\circ}-65^{\circ} \mathrm{N}\right.$, $\left.270^{\circ}-315^{\circ} \mathrm{E}\right), \mathrm{B}\left(30^{\circ}-70^{\circ} \mathrm{N}, 250^{\circ}-330^{\circ} \mathrm{E}\right), \mathrm{C}\left(30^{\circ}-75^{\circ} \mathrm{N}\right.$, $\left.250^{\circ}-360^{\circ} \mathrm{E}\right), \mathrm{D}\left(30^{\circ}-80^{\circ} \mathrm{N}, 210^{\circ}-330^{\circ} \mathrm{E}\right), \mathrm{E}\left(30^{\circ}-80^{\circ} \mathrm{N}\right.$, $\left.180^{\circ}-360^{\circ} \mathrm{E}\right)$. Eighteen different combinations of one, two, or three variables are considered for the predictor fields. Note that zonal and meridional wind components are combined together as a single predictor variable. The number of retained $\mathrm{EOFs}_{\text {predictor }} / \mathrm{EOFs}_{\text {predictand }} / \mathrm{CCAs}$ ranges between $4 / 4 / 2$ and $8 / 8 / 8$ combinations, accounting for 105 possibilities. The robustness of the SD is assessed by changing the size of the cross-validation subset that varies between $1,2,5,10$, and 20 months. The sensitivity analysis is carried out changing only one parameter at a time from the reference configuration, thus obtaining an ensemble of 130 possible parameter combinations per reanalysis, totaling $130 \times 12(1560)$ combinations. 

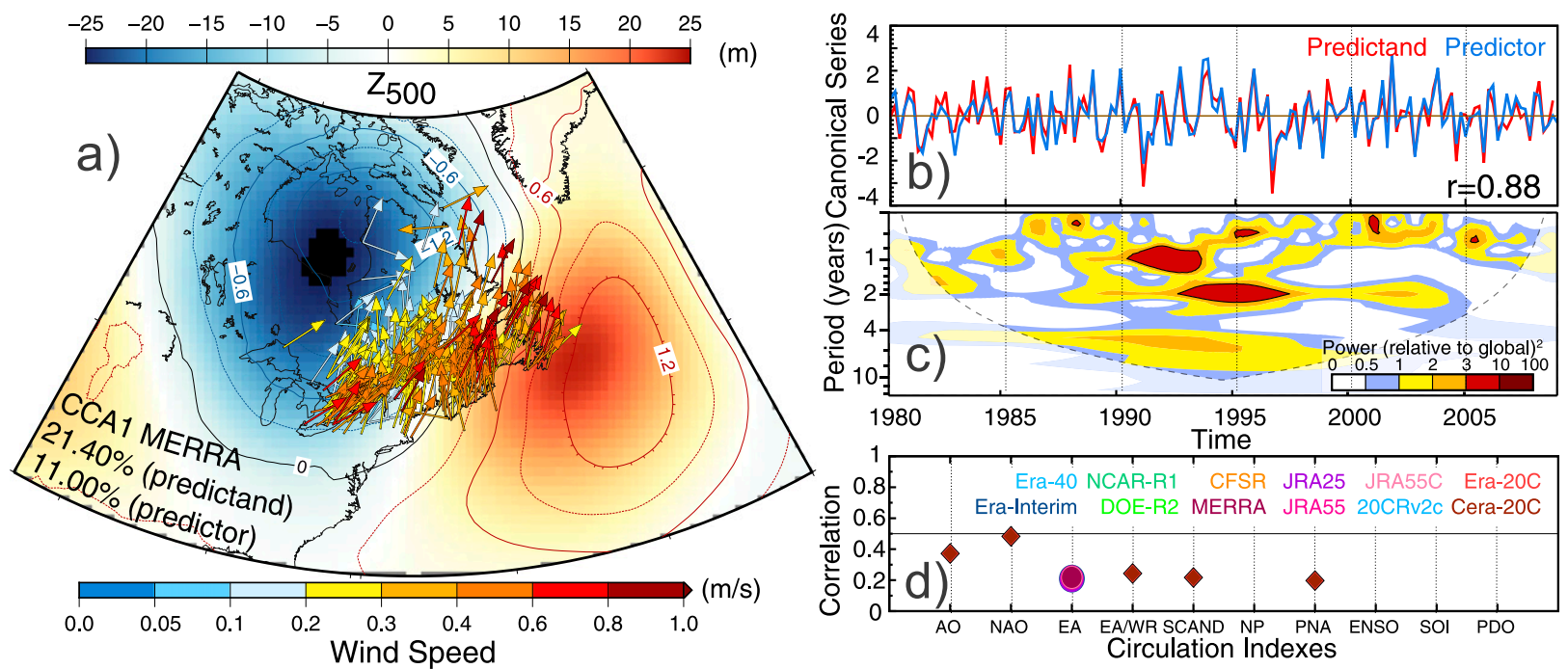

FIG. 2. (a) First CCA pattern (CCA1). Isolines stand for the SLP (hPa) and shadings are for the $Z_{500}$ regressed pattern (m) from MERRA as predictor; the vector field represents the observed wind anomalies as predictand (color scale). (b) CS1 of the predictor and predictand (blue and red, respectively) and their correlation. (c) Wavelet spectral power of predictor's CS. The colors represent the normalized variances scaled by the global wavelet spectrum (Torrence and Compo 1998). The cone of influence, beyond which edge effects become important, is indicated with a dashed line. The black contour lines highlight the significant areas $(p<0.05)$ with respect to a red-noise (first-order autoregressive) background spectrum. (d) Correlation between the CS1 from different reanalyses (colors; the twentieth century reanalyses are indicated with diamonds instead of circles for easier reading) and various circulation indices.

The accuracy of the SD estimations ( $\operatorname{wind}_{\mathrm{EST}}$ ) and the reanalysis winds ( wind $_{\mathrm{REA}}$ ) with respect to the WNENA observations ( wind $_{\mathrm{OBS}}$ ) is evaluated through four different metrics: the standard deviation ratio $\left(\sigma_{\mathrm{EST}, \mathrm{REA}} / \sigma_{\mathrm{OBS}}\right)$; the normalized root-mean-square error (RMSE $E_{\text {EST,REA }}$ $\left.\sigma_{\mathrm{OBS}}\right)$; the Pearson correlation coefficient $r$; and a modified Brier skill score $\beta^{\prime}$ where the added value of wind ${ }_{\mathrm{EST}}$ over wind $_{\mathrm{REA}}$ relative to wind $\mathrm{OBS}$ is evaluated (Lucio-Eceiza et al. 2019).

The comparisons with wind REA $_{\text {have been conducted }}$ choosing the closest grid points to each WNENA $\mathrm{WD}_{\mathrm{SD}}$ site. The training and evaluation period for sections 4 and 5 comprises the 1980-2010 interval for each reanalysis except for ERA-40 that ends on 2002. This period provides with a set of 150 monthly observations during the extended JJASO summer season, an interval which is close to a climatological standard normal (WMO 2011; the most recent one being 1981-2010).

\section{Downscaling experiment: Reference case}

This section analyses the results of the downscaling exercise using the reference configuration. This configuration uses window $\mathrm{B}$, the SLP field as predictor, retains five EOF modes from both predictand and predictor and four CCA modes, and uses a cross-validation subset of one month. Although it does not necessarily correspond to an optimal case, this configuration is still able to provide SD estimates that reasonably agree with the observations and illustrates the main large (predictor) associations to the local (predictand) ones. All the experiments in this section have been independently run for all reanalyses, but only the canonical patterns and series corresponding to the MERRA reanalysis are shown (Figs. 2-5), as the results are comparable, in general terms. The first four CCA patterns account for a retained variance of $62.5 \%$ for the predictand and $51.6 \%$ for the predictor. The number of retained EOF/CCA modes was chosen to describe a similar amount of variance than during wintertime $(59.3 \%$ for the predictand and $55.3 \%$ the predictor; see Lucio-Eceiza et al. 2019).

In the first coupled mode, the CCA1 of the SLP predictor field presents a northwest-southeast-oriented dipole structure (Fig. 2a), with negative anomalies centered over the Hudson Bay and positive anomalies over the south east shore of Newfoundland. In height the $Z_{500}$ field tends to enhance the meanders of the polar jet that follows the relative troughs and ridges. This configuration exerts meridionally oriented (southwest/south-northeast) anomalous winds that, as a result of the surface friction, tend to deviate from the geostrophic balance toward low pressure centers and are also significantly affected by the local topography in some specific areas (e.g., strait of Belle Isle or the shores of Labrador). The winds are more intense at the birth of the St. Lawrence River (southwest area), over the southern areas facing the St. Lawrence Gulf (Prince 

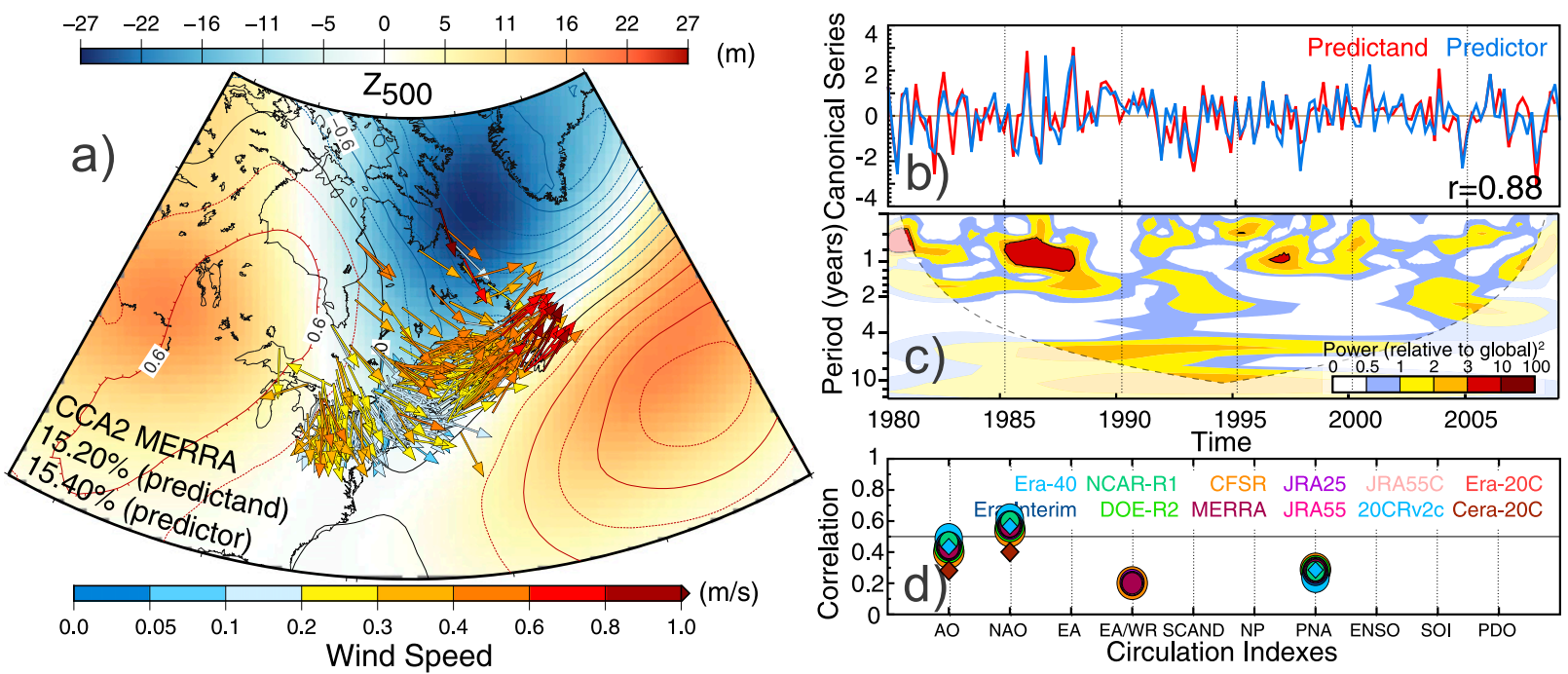

FIG. 3. As in Fig. 2, but for the CCA2 mode.

Edward Island, Nova Scotia, Anticosti Island), along the strait of Belle Isle (between Newfoundland and Labrador) and along the coast of Labrador. The positive phase of this mode of variability brings relatively colder and drier polar air masses from the north-northwest toward the westernmost areas of our region, while pushing the warmer and wetter Atlantic maritime tropical air masses from the south-southeast (Phillips 1990) across the easternmost coast. As a result, this produces a dipole of temperature anomalies with colder (warmer) than normal summers over the relative SLP negative (positive) anomalies (not shown). The encounter of cool and dry air masses with the humidity of the Great Lakes can lead to convective processes that ultimately generate thunderstorms. Following the path of the jet, these thunderstorms may entail a larger amount of precipitation to the east of the Great Lakes over Ontario, Quebec, and along the St. Lawrence River toward the east coast (not shown; Conrad 2009). This mode accounts for an explained variance of $21.4 \%(11 \%)$ of the predictand (predictor).

The associated predictor and predictand CS1s (Fig. 2b) show a significant $(p<0.05)$ correlation of 0.88 . The predictand's CS shows a significant $(p<0.05)$ correlation of 0.9 with the meridional regional wind anomalies, but a correlation of 0.2 the zonal winds. Thus, this mode is highly representative of the meridional circulations over the
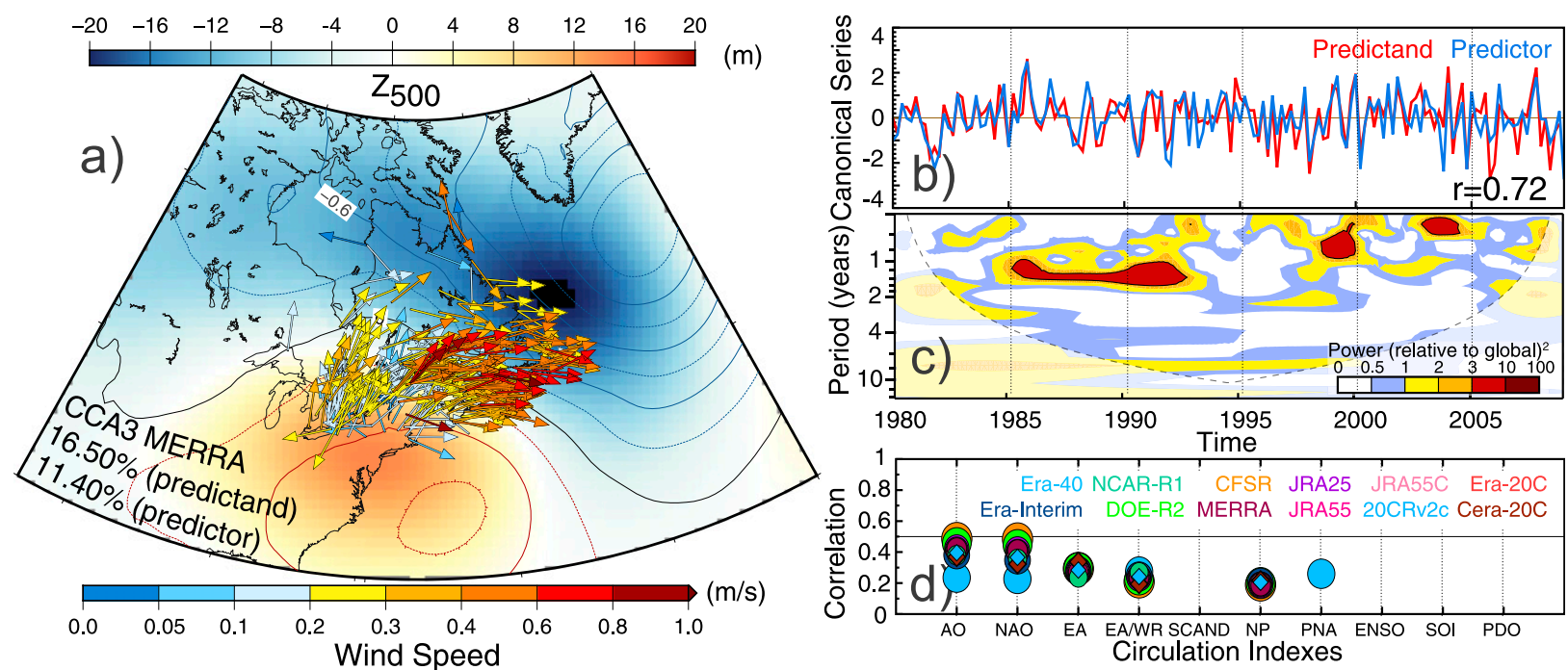

FIG. 4. As in Fig. 2, but for the CCA3 mode. 

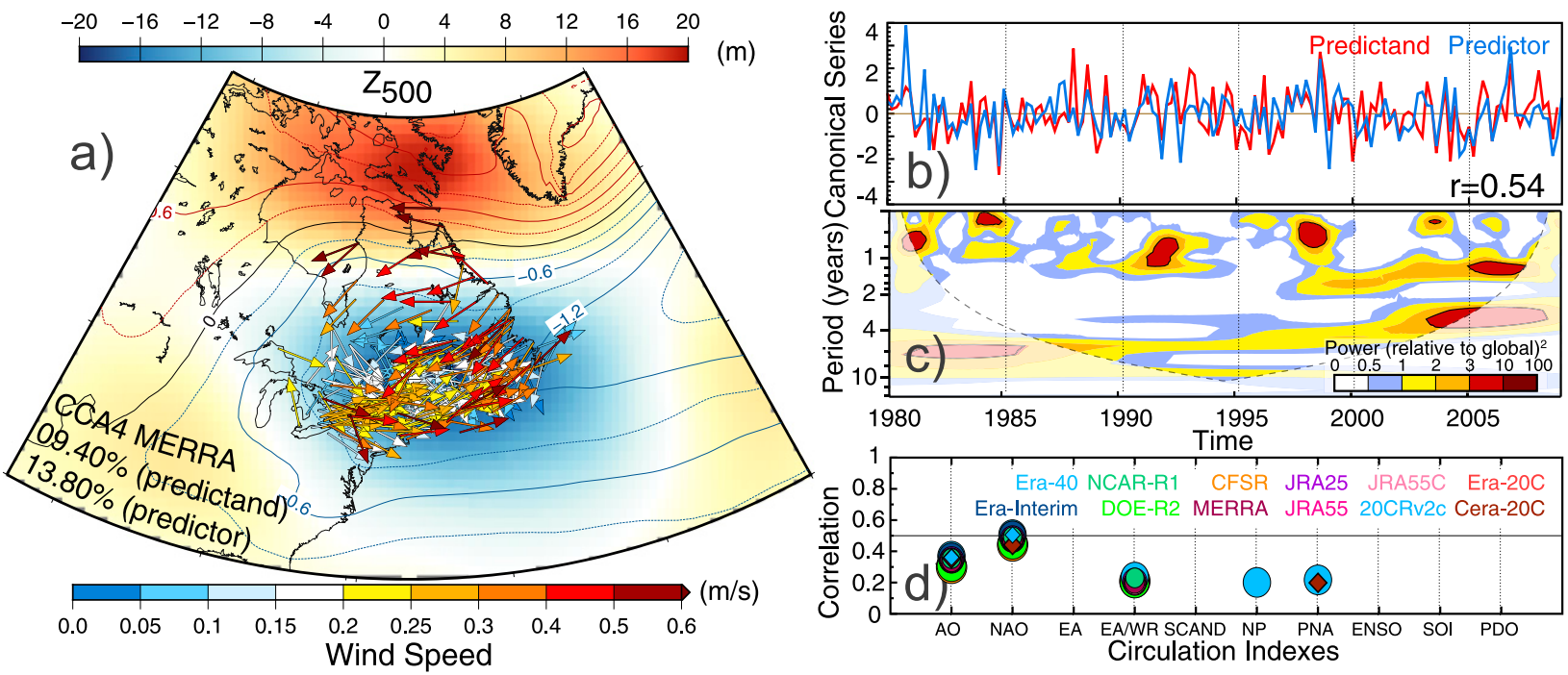

FIG. 5. As in Fig. 2, but for the CCA4 mode.

region. CS1 shows its highest variability during the 1990s, mostly concentrated at 1-2-yr time scales (Fig. 2c), diminishing toward the beginning and end of the training period, when the variability is mainly concentrated at intra-annual time scales. This first large-scale circulation mode cannot be clearly associated to any of the known main large-scale teleconnections that may affect this area (Fig. 2d).

In the second coupled mode (Fig. 3) the predictor field exhibits a saddle-shaped distribution with the positive anomalies oriented along the northwest-southeast axis, a negative anomaly over Greenland, and the col centered over Cape Hatteras. The winds are directed to the south in the southwest areas but abruptly turn counterclockwise facing a northeast orientation over the north of Newfoundland. The areas with the highest intensities are located in Newfoundland although in general high winds can be found all over the region except to the southeast of the St. Lawrence River. The location of these relative pressure highs allows the entry of colder and drier air masses from the north that cool most of the northeastern North America, except for the easternmost east coast (east of Newfoundland, Labrador, and Nova Scotia). Conversely, the entry of moister and warmer air sea masses over the east coast following the southerly winds favor precipitation over the easternmost region that comprises the whole of Labrador, Newfoundland, and Nova Scotia (not shown). The predictand (predictor) of this CCA2 mode explains the $15.2 \%$ (15.4\%) of the total variance. The predictor and predictand CS2s (Fig. 3b) show a significant $(p<0.05)$ correlation of 0.88 , as in the first mode. This mode presents a higher correlation with the regional zonal wind anomalies (0.6, significant at $p<0.05$ ). The CSs show a decade of larger variance at the beginning of the training period, mostly concentrated around interseasonal time scales (Fig. 3c), that is not regained until the end of the training period. CS2 shows its strongest teleconnection relationships with the AO and especially the NAO (correlation of 0.6 , significant at $p<0.05$, Fig. 3).

In the third coupled mode (Fig. 4a) the CCA3 of the predictor shows a southwest-northeast oriented dipole with the positive (negative) anomalies over the Atlantic Ocean at the east of Cape Hatteras, North Carolina (south of Greenland). The surface winds show weak meridional southerly anomalies over the Great Lakes that turn into quasi-zonal westerly winds over the rest of the region, more intense at the mouth of St. Lawrence River and until the Cabot strait. The circulation of colder continental and polar air masses follow the relative lows effectively cooling this area, while the relative highs transport the warmer and drier air masses of the center of the United States, effectively warming the region to the south of the St. Lawrence River (not shown). The precipitation anomalies also follow this dipole pattern, with more abundant than normal precipitations over the north, but drier over the south (not shown). This mode is responsible for the $16.4 \%$ $(11.4 \%)$ of explained variability for the predictand (predictor), with a correlation of 0.72 between their CSs. The regional zonal wind anomalies show significant $(p<0.05)$ correlation values of 0.78 with the predictands' CS (Fig. 4b). This mode shows enhanced variance throughout the second half of the training period, which is accompanied by a seemingly slight negative trend. The variability is mostly intra-annual or interseasonal along the second part of the training period (Fig. 4c) and of 1-2 years along the 


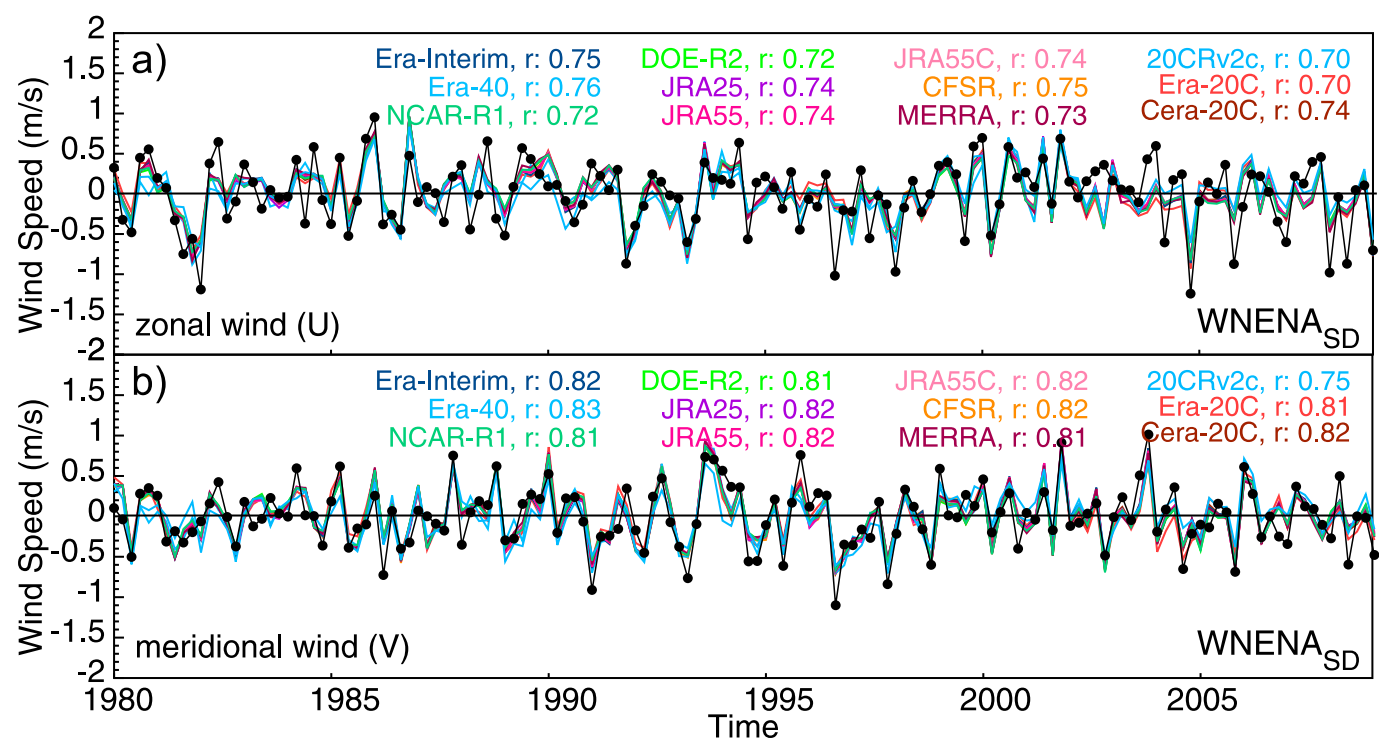

FIG. 6. Regional wind components obtained from the SD estimates with the reference configuration and WNENA $_{S D}$ in black for (a) zonal and (b) meridional wind. Estimates obtained using different reanalyses are indicated with different colors. The correlation values between the estimations and the observations are also indicated.

first half, especially between the years of 1985 and 1995. The coupled mode shows some resemblance with NAO and AO teleconnection patterns with correlations of $\sim 0.5$ (significant at $p<0.05$, Fig. 4d).

In the fourth coupled CCA mode (Fig. 5a), the predictor field presents a meridional dipole with the center of negative anomalies over the middle of the North Atlantic (out of frame) that stretches across the whole area to the Great Lakes, the positive anomalies are centered at the east of Greenland, while at $Z_{500}$ the center of negative (positive) anomalies of the dipole is situated over New Brunswick (Baffin Island). This configuration derives in a pronounced cyclonic flow, showing particularly intense (albeit weaker than any other CCA) and easterly winds north of Labrador and Quebec. The positive phase of this fourth mode allows for the transport of continental colder air masses cooling most of the area, except for the northern of Quebec and Labrador (not shown). These air masses in contact with the humid Great Lakes and St. Lawrence River and Gulf, foster more abundant than normal precipitations over this whole region. This mode is responsible for the $9.4 \%$ (13.8\%) of explained variability for the predictand (predictor). The correlation between the CS4s is 0.54 (Fig. 5b), substantially lower than for the previous modes. Except for a brief period around 1985, the CSs show a similar variance along the whole training period. The variability is mostly intraannual or interseasonal (Fig. 5c) although it presents variability at longer time scales ( $2-4$ years) throughout the last decade. This mode is also best related with NAO teleconnection pattern, showing correlation values close to 0.5 (significant at $p<0.05$, Fig. $5 d$ ).

The cross-validated estimates of wind speed anomalies obtained from the reference case show that the meridional wind components are (on average) better estimated (correlations ranging $0.75-0.84, p<0.0$ ) than the zonal ones $(0.70-0.76$, Fig. 6$)$. This is because the variability of meridional wind anomalies, more relevant than the zonal ones during summer, is better captured by the CSs: the regional meridional anomalies show a larger correlation value, and with a higher-order CS (0.9, significant, with CS1), than the zonal ones $(0.78$, also significant, with CS3). The variance of the estimated wind components is underestimated, as expected when using methods based on linearity of covariations (Fowler et al. 2007). However, the standard deviation ratios for the meridional component are still larger (range 0.82-0.92) than those of the zonal component (0.720.81 ). Although there is some spread in the estimations obtained from the different reanalyses, they are very similar in general.

In view of the CCA results it can be then said that the summertime surface wind variability responds, to a large extent, to changes in the large-scale circulation dynamics. Additionally, the validation of the SD model suggests that the monthly surface wind over the region can be estimated (Fig. 6) from the variability of four main modes of circulation (Figs. 2-5). The estimations are, in general, very similar regardless of the used reanalysis 


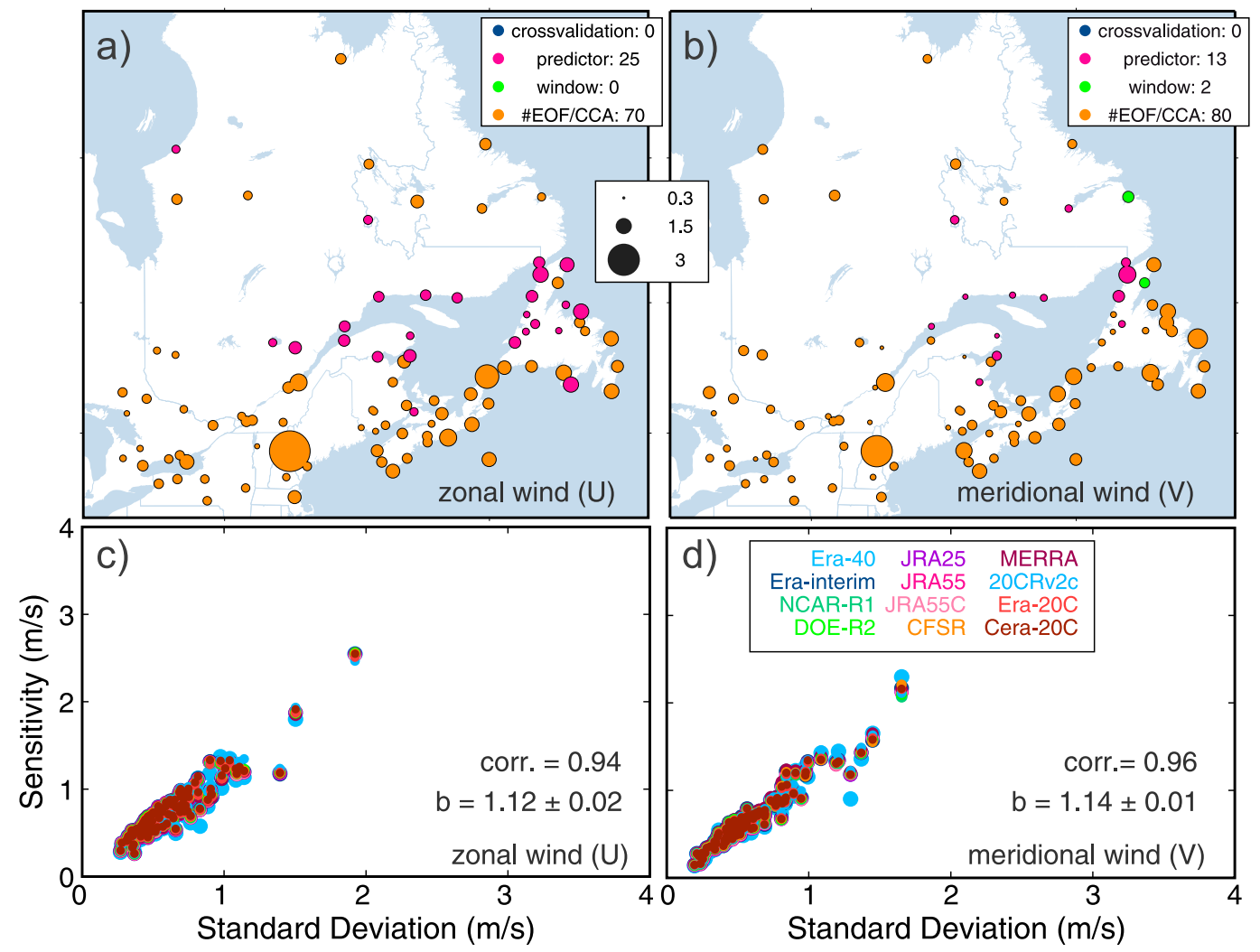

FIG. 7. (top) Methodological sensitivity at each location for (a) zonal and (b) meridional wind to the change of one parameter of the SD reference configuration at a time. The parameter that shows the largest sensitivity is depicted at each site. The diameter of the circle is proportional to the sensitivity (in $\mathrm{m} \mathrm{s}^{-1}$; see legend). The number of sites where each parameter is predominant is also indicated. (bottom) Sensitivity vs wind standard deviation at each site for (c) zonal and (d) meridional component for each reanalysis (colors). For each wind component both the correlation and the slope of the linear regression $b$ together with the confidence interval calculated at $p<0.05$ are given.

products. These estimates are, however, obtained from a single parameter configuration that does not allow us to assess the robustness of the methodology to changes in its configuration. The latter is explored in the next section.

\section{Methodological sensitivity assessment of wind estimations}

\section{a. Sensitivity of wind estimations to model configuration}

This section assesses the robustness of the SD methodology to different parameter configuration choices using the reference configuration as the basis for the sensitivity analysis. In total an ensemble of 1560 possible combinations has been applied $(130 \times 12$, see section 3$)$.

The uncertainty arises from the methodological sensitivity of the estimates. It is calculated at each site and for each wind component and reanalysis as the average of the differences between the maximum and minimum estimated values at each time step obtained from the ensemble of parameter choices. The analysis is conducted for each of the parameters individually, calculating a sensitivity value for each of the four subensembles (i.e., window size, predictor field, number of retained EOF/CCA modes, and cross-validation subset; see section 3 for the number of options employed in each case). This procedure permits us to identify which parameters of the method configuration present the largest sensitivity at each site (and wind component), allowing for a spatial analysis of the distribution of the methodological uncertainty (Figs. $7 \mathrm{a}, \mathrm{b})$. The sensitivity (in $\mathrm{m} \mathrm{s}^{-1}$ ) associated with each of the parameters is proportional to the diameter of the circle. For an easier visualization only the most sensitive parameter is indicated at each site.

As with the reference configuration, the spatial distribution of the methodological sensitivity is shown for the MERRA reanalysis alone (Figs. 7a,b) since the rest of reanalyses show similar results. The number of retained modes accounts for the largest amount of 


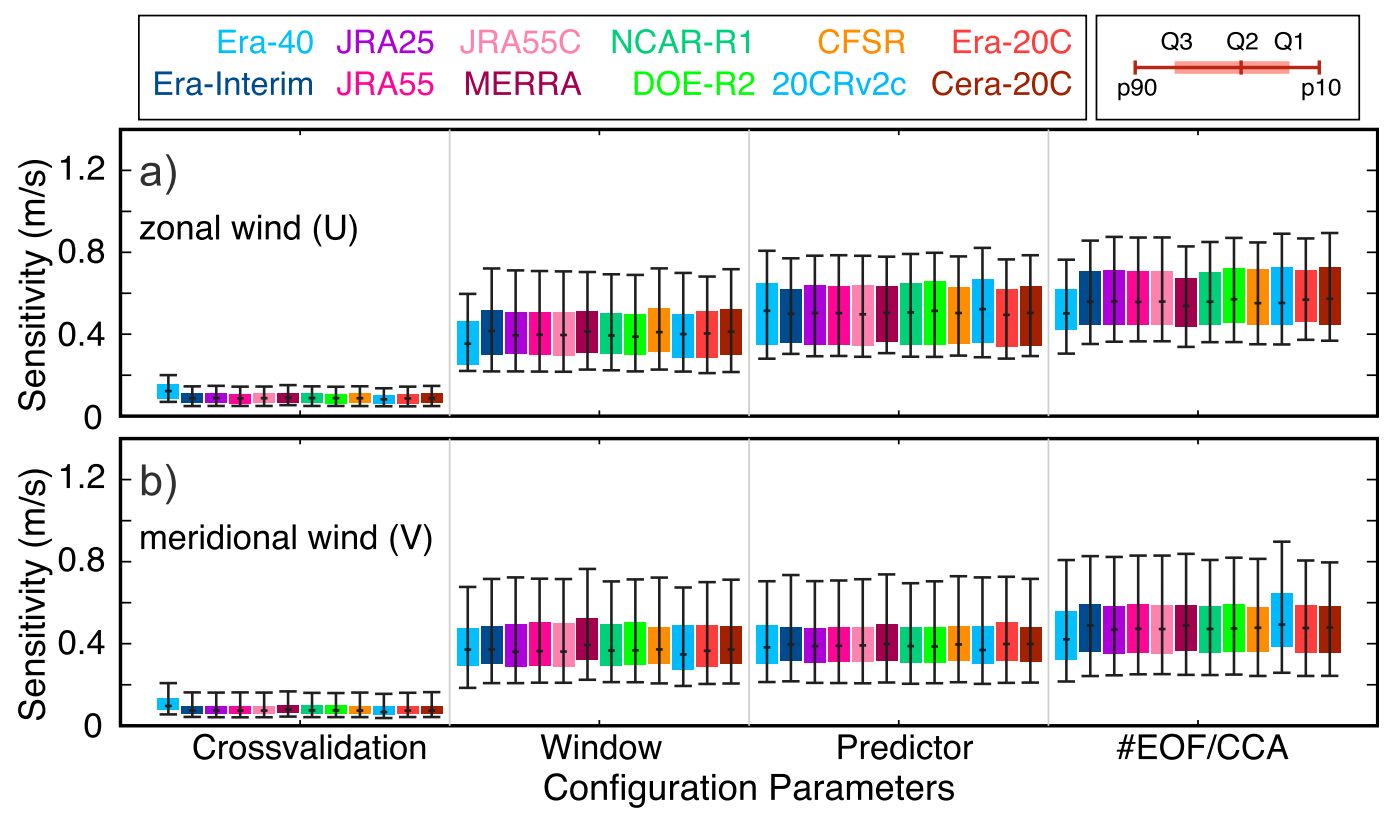

FIG. 8. Methodological sensitivity of (a) zonal and (b) meridional wind to the change of one parameter of the SD reference configuration segregated according to the reanalysis used as predictor field source (color) and configuration parameter. Each boxplot is constructed with the information from all sites.

methodological uncertainty at the majority of the sites for both components. However, there is a subgroup, regionally distributed over the northern part of the Gulf of St. Lawrence, where the most relevant parameter corresponds to the predictor variable. The sites with largest sensitivity values are in general located in the windiest places, where the variability is also highest (Fig. 1a): over eastern Newfoundland, narrow straits, along the shore, and on top of Mt. Washington. The sensitivity value at each site as a result of considering all possible configurations explored (130 experiments) is also calculated and represented in the dispersion diagrams of Figs. 7c and 7d. This helps in identifying a potential association between the sensitivity and the variability of the wind at each site, represented by its standard deviation. There is a clear linear correspondence for both cases (correlations above 0.9) that holds for every reanalysis. The sensitivity for both zonal and meridional components increases with the standard deviation at a similar rate.

Gathering the sensitivity values from every site together and segregating them by parameter, reanalysis and wind component, the sensitivity range of the whole region can be explored in Fig. 8. For both components the sensitivity ranges related to the number of retained modes is similar in magnitude and larger than the sensitivity associated to the other parameters, specially the cross validation. Therefore, the methodology employed seems to be robust without regard to the cross-validation subset used. For zonal winds there is a clearer distinction between the sensitivity ranges associated to the predictor choice and the window size, being the former slightly larger in general. All reanalyses show very similar results among them.

As we have seen the SD estimates are very similar regardless of the choice of the reanalysis, showing comparable sensitivity ranges even at the site level. On the other hand, due to the fact that some of the reanalyses reach very high resolutions and detail in reproducing surface physics (e.g., CFSR and MERRA; see Table 2), it is worth evaluating how their summertime estimated winds compare to observations and SD estimates.

\section{b. Evaluation of the predictive skill of reanalysis wind and estimations}

This section utilizes a different parameter configuration than that of the reference, chosen to offer a substantially higher explained variance and better wind estimates than the reference set. This parameter configuration (skillful configuration hereafter) uses the smallest domain size (A), 7/7/6 retained $\mathrm{EOFs}_{\text {predictor }} / \mathrm{EOFs}_{\text {predictand }} / \mathrm{CCA}$ modes and a cross-validation subsampling interval of 1 month. It has been chosen to be the same one than for wintertime (Lucio-Eceiza et al. 2019), which also showed a high total explained variance with high correlation values for all of its CSs. The modes obtained from this skillful configuration present a total explained variance with a range of $69 \%-71 \%(60 \%-65 \%)$ for the predictand 
SD Estimation
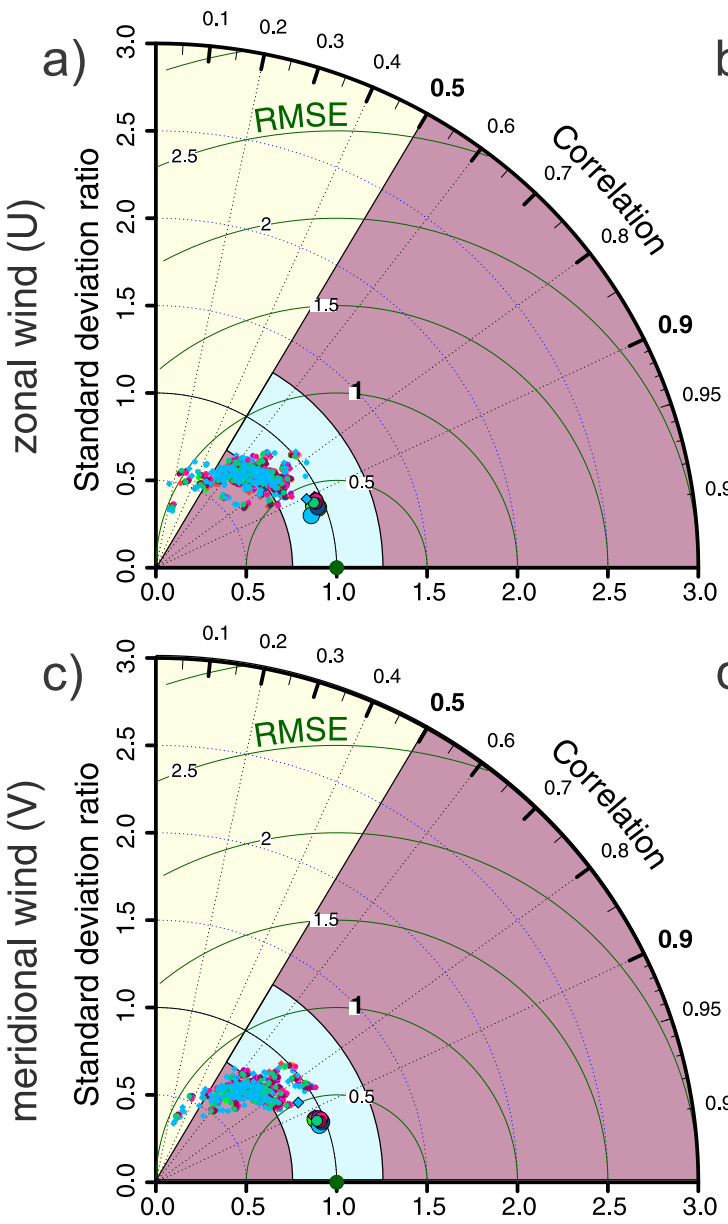
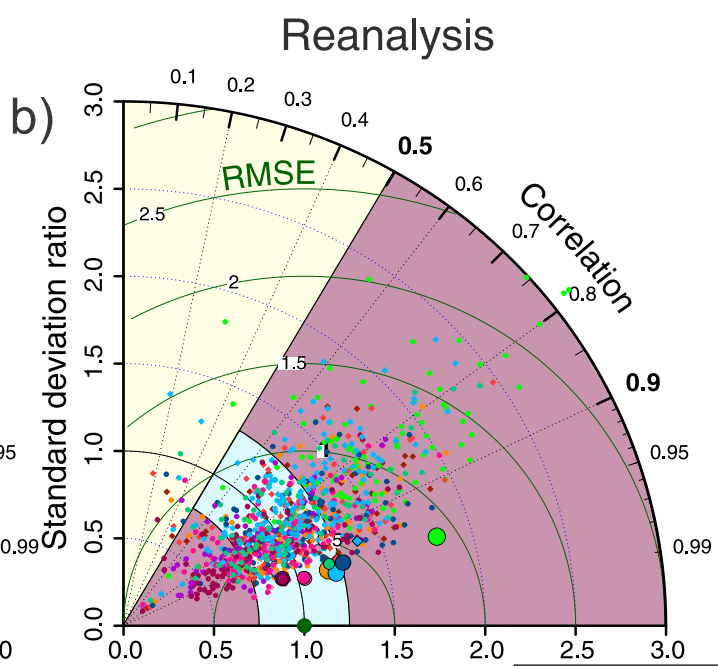

$\begin{array}{llllll}0.1 & 0.2 & \text { Era-40 JRA25 } & \text { MERRA }\end{array}$
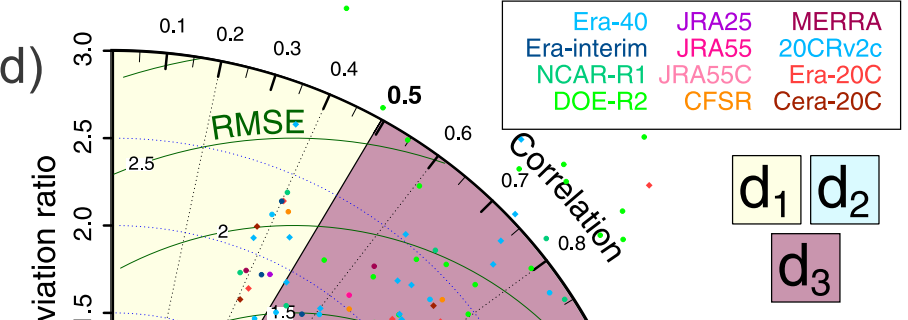

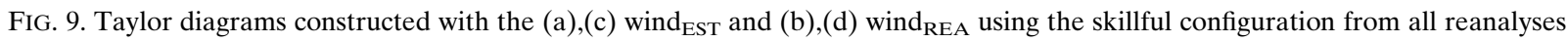
(colors) with respect to the observations $\left(\right.$ WNENA $_{S D}$ ). The correlation values between wind EST $_{\text {(or wind }}$ REA) and WNENA $\mathrm{WD}_{\mathrm{SD}}$ are provided in the clockwise angle scale, and the standard deviation ratios are given by the radial coordinate. The normalized RMSE values are indicated in concentric green circles. The large dots correspond to the regional averages while each small dot depicts a particular observational site. (a),(b) Zonal and (c),(d) meridional wind components. Each Taylor diagram is divided in 3 domains according to correlation values and standard deviation ratios: domain $1\left(\mathrm{~d}_{1}\right.$, light green) encompasses sites with poor correlation values $(r<0.5)$; domain $2\left(\mathrm{~d}_{2}\right.$, blue $)$ comprises those with high correlation values and ratios $\left(r \geq 0.5\right.$ and $\left.\sigma_{\mathrm{EST}, \mathrm{REA}} / \sigma_{\mathrm{OBS}} \in[0.75,1.25]\right)$. Finally domain 3 $\left(d_{3}\right.$, violet) corresponds to sites with good correlation but poor ratios. Note that some of the dots belonging to $d_{3}$ are located outside of the diagram as can be appreciated in (b) and especially in (d).

(predictor), where the reference range is $61 \%-63 \%(50 \%-$ $55 \%$ ) for the predictand (predictor), presenting similar spatial patterns to those of the reference configuration for their highest order CCAs (not shown). This skillful configuration has been used to compare the added value of the SD wind estimations ( wind $_{\mathrm{EST}}$ ) with respect to the winds simulated by the reanalyses ( wind $_{\mathrm{REA}}$ ), both site by site and regionally.

Figure 9 shows a comparison between wind $\mathrm{EST}_{\text {(Figs. }}$ 9a,c) and wind $_{\text {REA }}$ (Figs. 9b,d) by means of a Taylor diagram (Taylor 2001; details in Fig. 9) both at each site collocated with the observations (WNENA SD; $_{\text {; small circles) }}$ and regional averages (larger circles). The correlations of wind $_{\mathrm{REA}}$ at the local level are overall higher $(0.70-0.95)$ than for wind ${ }_{\mathrm{EST}}(0.50-0.88)$. The estimated standard deviation

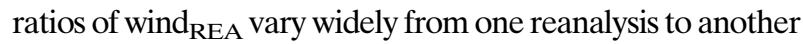
(the majority of sites ranging from 0.4 to 2.5 ) while wind EST $_{\text {T }}$ offers higher and very homogeneous ratios of variance regardless of the source (most of the sites ranging from 0.5 to $0.9)$. The regional SD estimated meridional wind component shows a lower inter-reanalysis variance than the zonal one. The latter cannot be appreciated at the site level. The regional averages show, as expected, better results than the individual estimates, departing from their centroids. These results can be attributed to the fact that the local noise is cancelled while the regional signal is amplified. Similar to the 
individual sites, regional wind $\mathrm{REA}_{\mathrm{REA}}$ show higher correlation values (0.94-0.97 for zonal, $0.90-0.97$ for meridional) than $\operatorname{wind}_{\text {EST }}(0.90-0.94$ for zonal, $0.87-0.94$ for meridional), all significant $(p<0.05)$, but in contrast the range of their estimated variances is much wider $(0.92-1.80$ for zonal, 0.93 1.98 for meridional) than for SD estimations $(0.89-0.97$ for zonal, $0.92-0.98$ for meridional).

Between half and 2/3 of the SD estimated sites show relatively high correlation values and a realistic characterization of the variance $\left(\mathrm{d}_{2}\right.$ region in blue in Figs. $9 \mathrm{a}$ and $9 \mathrm{c})$ and are more or less homogenously distributed over the whole region (not shown). In contrast, only around 5\% of the sites present low correlation values $\left(\mathrm{d}_{1}\right.$ region, in yellow) and are located in places with directional channelings and overall complex orography (ridges, straits, intricate shores, not shown). The reanalyses show consistently better correlation values than SD estimates all over the region. wind $_{\text {REA }}$ also show a much wider range of variances, thus, their relative skill respect to wind $\mathrm{EST}_{\mathrm{E}}$ can drastically change depending on the chosen reanalysis, from being consistently poorer (e.g., $\beta^{\prime}>0$ in $>85 \%$ of the sites for DOE-R2,

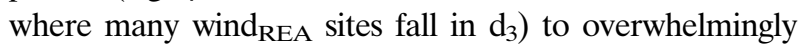
better (e.g., $\beta^{\prime}>0$ in $<30 \%$ of the sites for JRA55C).

$\mathrm{SD}$ estimations yield very similar results that are mostly indifferent to the source reanalysis. The reanalysis wind outputs on the other hand show a wide range of results, mainly attributed to the differences in the reproduced variance. An optimized parameter choice (skillful configuration) is able to offer high correlation values and a realistic variance characterization both at the local and regional level for wind $\mathrm{EST}_{\mathrm{ES}}$. The correlations of the SD estimates are still lower than those obtained from wind REA $_{\text {, which can be attributed }}$ to the fact that the SD method linearizes the relationships between the large and the local scale, a large-scale description that the reanalyses are very well suited to reproduce on the other hand. However, the reproduced variance given by wind ${ }_{\mathrm{EST}}$ is an improvement over the reanalysis results, especially for sources with less realistic characterisations (e.g., DOE-R2), since they are able to offer an imprint of the local characteristics that the reanalyses by their crude resolution are unable to do.

\section{Wind climatology reconstruction}

One of the main assets of the SD methodologies lies on the extrapolation of estimates for periods with no availability of observational data. These exercises can be focused on future climate scenarios and their impact over a particular region (e.g., Pryor et al. 2006; Najac et al. 2009) but can also be, as in our case, oriented to estimate past variability at longer time scales (e.g., García-Bustamante et al. 2012, 2013). The validity of these projections, however, relies on the assumption that the relationships between predictor and predictand, that were established during the training period, will remain stationary in time (e.g., von Storch et al. 1993), but there is no way to a priori assure this. For that reason the training period has to be long enough to account for a wide range of circulation situations. The 1980-2010 time span is close to a climatological standard normal (WMO 2011), which hopefully will help to alleviate this methodological limitation.

Our objective in this section is to reconstruct the local surface wind by means of projecting the predictor anomalies during the reconstruction period, herein 1850-2010 in the longest case allowing an extended analysis of the wind behavior from intra- to interannual and multidecadal scales, onto the CCA patterns obtained during the training period. For this exercise we do not only use all available global reanalyses, but also two long SLP observational gridded datasets (ds010.0 and HadSLP2r; see Table 2), for which, unlike during sections 4 and 5, we preserve their original trends. Additionally, we conduct a methodological sensitivity analysis similar to that of section $5 \mathrm{a}$, which provides us with a measure of the uncertainty associated to the past wind component estimates. Since the observational gridded datasets only contain the SLP variable, the reconstruction exercise is restricted to that variable alone, also for the reanalyses datasets. On the other hand, due to the negligible influence of the crossvalidation subset size on the estimated uncertainties (see the sensitivity in Fig. 8) this parameter has not been taken in account. In total $105 \mathrm{EOF} / \mathrm{CCA}$ choices and 5 different domain sizes are combined together, obtaining 525 possible parameter variations per predictor source, totaling an ensemble of 7350 possible model configurations $(525 \times 14)$.

As an initial step, four CSs have been projected from the CCAs obtained during the 1980-2010 training period with the reference configuration (Figs. 10a-d). As can be appreciated, the variability of the projected CSs remains mostly unchanged beyond 1980-2010 and further back until the beginning of the longest conventional reanalysis, the NCAR-R1 (starting at 1948), indicating that the major circulation modes identified during the training period were still relevant back then. Additionally, and as anticipated in section 4, the majority of the reanalyses show an agreement between the different projected series that is more or less maintained until the 1930s, when the ensemble of the large-scale sources shows some spread to the past: CERA-20C's CS1 and CS3 show a particularly intense negative phase during the late 1920s, and 20CRv2c's CS2 is consistently biased toward negative values. As these differences are 

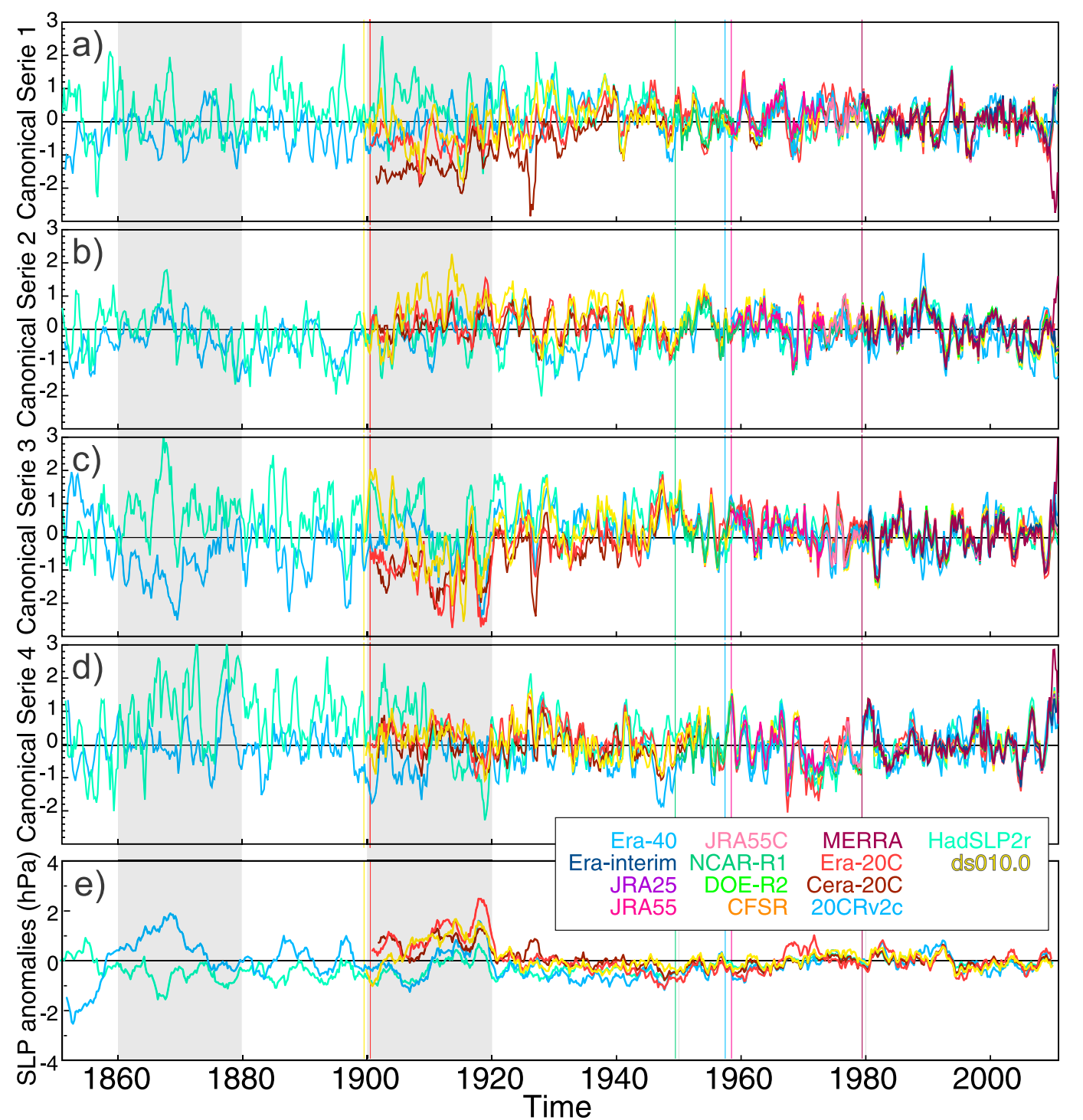

FIG. 10. (a) Extension of the first CS from the reference configuration to the whole temporal length of each reanalysis/database (inset, in colors). The series are 2-yr low-pass filter outputs. The vertical bars (same color as its corresponding reanalysis) indicate the starting date of each reanalysis/database (see Table 2). (b)-(d) As in (a), but for second to fourth CSs. (e) SLP anomalies of the five longest datasets over the region of interest. The CSs and SLP anomalies are computed over the 1980-2010 training period and are presented as 2-yr low-pass filter outputs.

even more notorious prior to 1920 , for a more in detail discussion the 1900-20 and 1860-80 intervals have been highlighted.

Figure 10e shows the regional average SLP anomalies calculated over the reference configuration's domain (B, the one used for the projection of the CSs) for the whole extension of each of the five longer predictors. As expected from Figs. 10a-d, the variability of the ensemble of regional SLP averages is comparable to a large extent until the 1930s, when the spread starts becoming more apparent. Through the period 1900-20
ERA-20C/CERA-20C evidence a sustained positive bias respect to 20CRv2c/HadSLP2r, although they all follow similar long-term tendencies. While the similar behavior between ERA-20C/CERA-20C is to be expected, the 20CRv2c/HadSLP2r clustering can be explained as there is a certain degree of overlap between HadSLP2 and the SLP data assimilated by 20CRv2c: the marine observations of both stem from different versions of the ICOADS v2 (ICOADS v2.2 for HadSLP and ICOADS v2.4 and v2.5 for $20 \mathrm{CRv} 2 \mathrm{c}$; Ferguson and Villarini 2014). The relative differences 


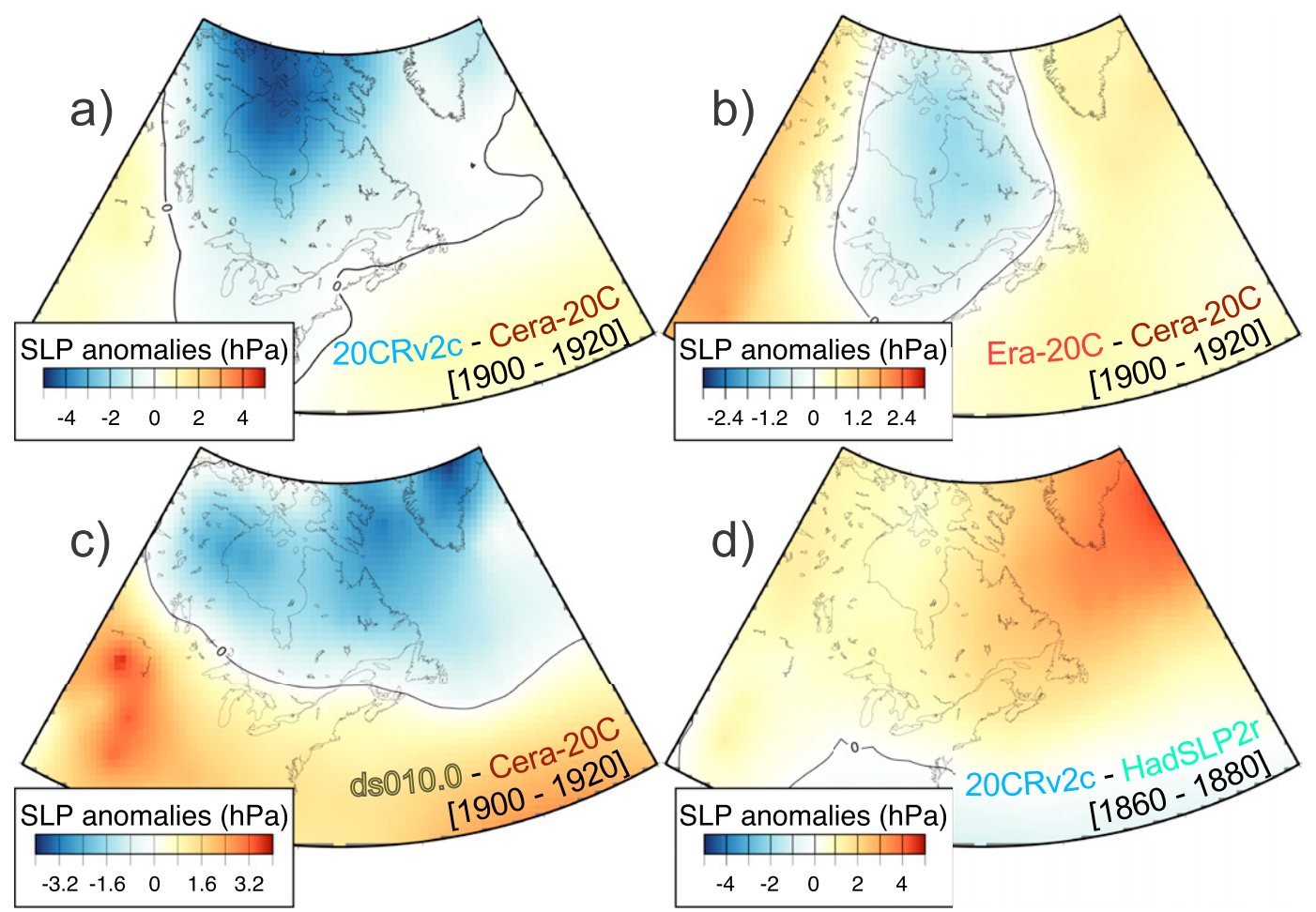

FIG. 11. (a) Differences between 20CRv2c and CERA-20C SLP anomalies for the 1900-20 interval, highlighted in Fig. 10; (b) as in (a), but for ERA-20C and CERA-20C; (c) as in (a), but for ds010.0 and CERA-20C; (d) as in (a), but for 20CRv2c-HadSLP2r and the 1860-80 interval (also highlighted in Fig. 10).

seen during 1900-20 can be mostly attributed in terms of a negative bias of 20CRv2c over the continent in comparison with CERA-20C (Fig. 11a). This relative low pressure system strengthens the circulation system of the first CCA mode (Fig. 2a), which can be seen in the relatively higher CS values for 20Crv2c (Fig. 10a). This geographical difference is less pronounced for ERA-20C than for CERA-20C (Fig. 11b), also reflected in the variability of CS1 (Fig. 10a). The distinct positive bias for ERA-20C/CERA-20C during 1900-20 with respect to their long-term variability for the most recent (1920-2000) period might suggest inhomogeneity problems for this period. This issue has already been pointed out by Befort et al. (2016), albeit indirectly. Their study compared the long-term extratropical count trends found between ERA-20C and 20CRv2c reanalyses and showed drastically different results during 1901-30 and 1931-60 periods. Wang et al. (2013) found several inhomogeneity problems in the cyclone counts of the early years of 20CRv2c that were mostly related to the fewer available SLP observations to constrain the analyzed field, and similar problems can be expected for ERA20C as well (Befort et al. 2016). A more in-depth analysis about the apparent ERA-20C/CERA-20Cs inhomogeneities is, however, beyond our current work. The ds 010.0 dataset mostly follows the ERA reanalyses, although it converges toward the other two at the beginning of the period. For instance, the differences between ds 010.0 and CERA-20C (Fig. 11c) exert a relatively stronger westerly fluxes for ds010.0, as it is reflected on its more positive (less negative) CS2 (CS3) values (Figs. 10b,c).

Before the 1900s even larger differences can be observed between HadSLP2r and 20CRv2c, and particularly during the first decades. For instance, during the 1860-80 period the regional biases may reach up to $2 \mathrm{hPa}$ for some dates. This bias is zonally distributed (Fig. 11d) and weakens the westerly flows of 20CRv2c in comparison with HadSLP2r, as reflected in the consistently negative phase of CS3 and lower values of CS4 for 20CRv2c (Figs. 10c,d). The analysis conducted in LucioEceiza et al. (2019) over wintertime suggests that these discrepancies might be more related with problems in 20CRv2c SLP data, and it is safe to assume that these types of errors could likely affect the data during summertime as well.

The reconstruction of the surface wind regional anomalies derived from the reference configuration is presented in Fig. 12 (color lines). As expected from the behavior of the CSs the estimations show an agreement among them until the 1930s, closely following the observations (black thick line) throughout the whole observational period 1953-2010. Between the 


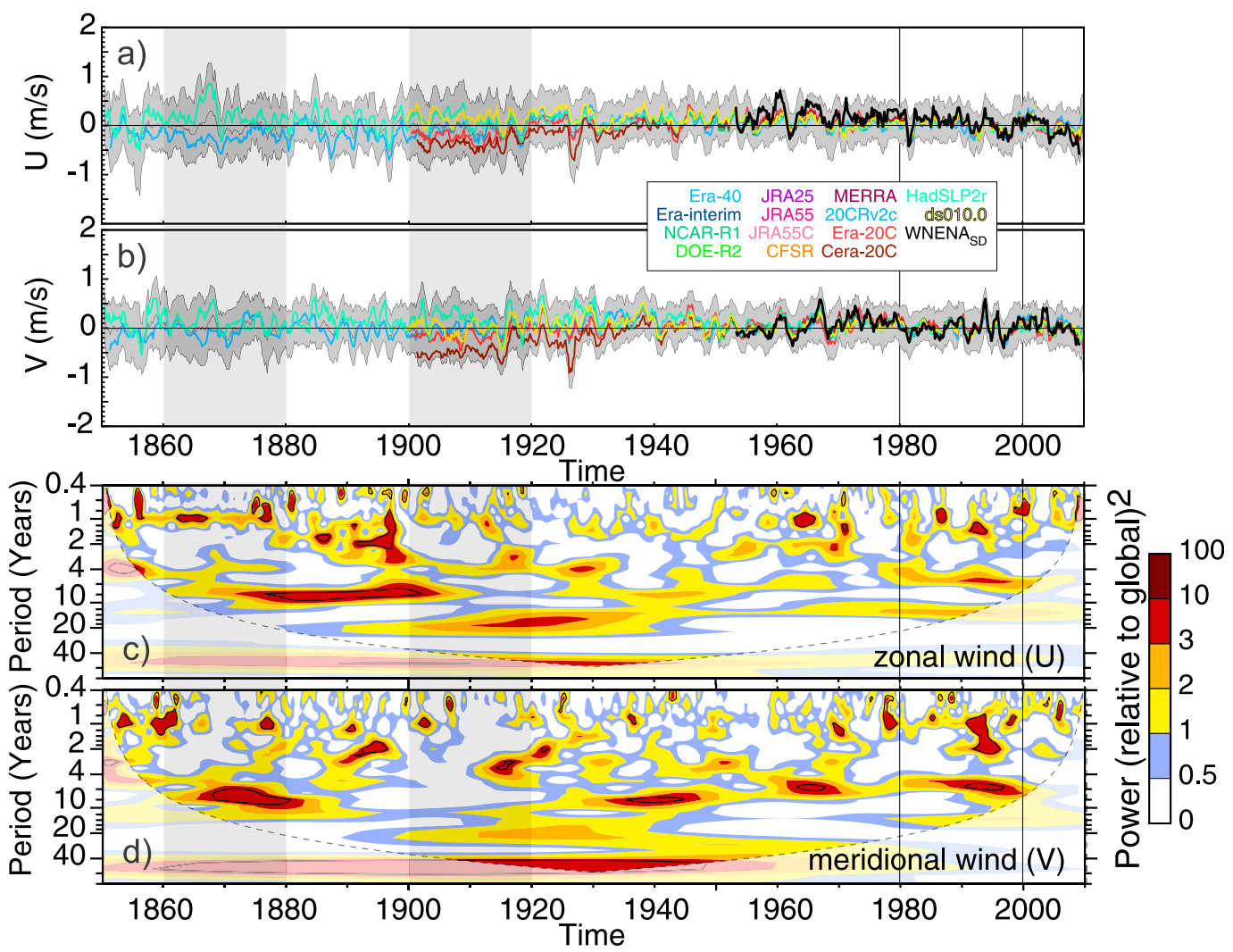

FIG. 12. (top) Regional wind reconstruction with its associated uncertainty for (a) zonal and (b) meridional wind anomalies. The observations are presented with black lines. The median of the multiple configuration ensemble is given with a dark gray line, and the spread is expressed as the gray envelope with gray border. The estimates from the reference configuration for each predictor dataset are represented in color (see legend). The series are 2-yr low pass filter outputs. (bottom) Wavelet spectral power of the ensemble median for (c) zonal and (d) meridional wind anomalies.

1900s and 1920s (shadowed in gray) ERA-20C and especially CERA-20C show a relative negative bias on the regional estimates respect to the rest of sources. This is particularly accentuated for the meridional component in CERA-20C and is related to the marked negative phase of its first circulation mode (Fig. 10a) that exerts anomalous northerly circulations. Differences between the zonal estimations from 20CRv2c and HadSLP2r can also be appreciated between 1850 and 1880 even showing opposite in phase variations related to variations of their respective CSs (Figs. 10a-d) that reinforces the westerlies for HadSLPr while it stagnates or even reverses the flow for $20 \mathrm{CRv} 2 \mathrm{c}$. This figure also presents the uncertainty of the estimates derived from the sensitivity experiments similar to what was done for the calibration period that generated an ensemble of 7350 members and is indicated with a graded band of gray shadings. While the uncertainty bandwidth remains more or less constant for most of the reconstruction period it becomes notably wider between the 1900s-20s and $1850 \mathrm{~s}-80 \mathrm{~s}$, where the SLP from the different predictor datasets showed larger discrepancies.

Both wind components present variability at interannual time scales (1-4 years; Figs. 12c,d). In fact, the first (1850-90) and last (1970-2010) decades are particularly active in this regard. But they also show variability at longer time scales that could not be identified with the previous exercise (section 4): on decadal time scales the variability is more evenly distributed for the meridional component while mostly confined to the $1850-1900$ period in the case of the zonal component, and at longer time scales (20-40 years) is specially notorious during the first half of the twentieth century. No overall long-term trends are observed throughout the whole reconstruction.

The reconstruction of the regional surface zonal and meridional wind components allows an expansion of the wind estimates beyond the observational period in a multidecadal to centennial context. The estimations produced by different predictor sources show a high 
degree of agreement until the beginning of the twentieth century. Further back, when issues with the quality or quantity of data may come into play, the uncertainty increases. We are able to identify the variability at longer (interdecadal; i.e., 10-40 years) time scales than during the training period alone.

As anticipated in section 2a, the observational data

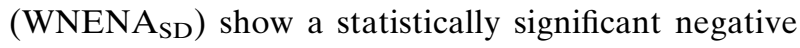
trend that for regional zonal wind anomalies accounts for $-0.12 \mathrm{~m} \mathrm{~s}^{-1}$ decade $^{-1}$ during the training period and becomes more pronounced $\left(-0.66 \mathrm{~m} \mathrm{~s}^{-1}\right.$ decade $^{-1}$, also significant) during $2000-10$. Around $20 \%$ (50\%) of the 7350 members of the ensemble and 9 (11) of the 12 global reanalyses exhibit statistically significant negative trends during the training (2000-10) period for regional zonal anomalies (not shown). These results contrast with what was observed for the cold season in Lucio-Eceiza et al. (2019), where no statistically significant negative trends in either of the wind components were found. This differential behavior across seasons is in accordance with previous studies making use of both observations (Wan et al. 2010) and reanalysis data (Torralba et al. 2017) that have already shown seasonal variability on the wind speed trends over this region, presenting larger negative values during summer months. This is also supported by records of observational land sites all over the world following a multifactorial phenomenon commonly referred as wind stilling (e.g., Vautard et al. 2010; McVicar et al. 2012; Azorin-Molina et al. 2017).

This behavior can be partially explained in terms of a weakening of the second and especially third CCA modes (Figs. 3 and 4) that contribute to weak westerly winds. This is evidenced by the significant negative trends shown by their corresponding predictand's CSs during 2000-10 (followed by 11 of the 14 predictor sources in the case of CS3, 4 in the case of CS2, not shown). Although the predictor's (i.e., SLP field's) CSs present weaker and nonstatistically significant negative trends than the predictand, the SLP anomaly fields used to calculate them present zonally distributed trends, positive (negative) to the north (south) of our region, with subregions of significant negative (positive) trends along the southeastern coast of the United States (over northern Quebec, not shown) and are consistent across different datasets (e.g., Hartmann et al. 2013). These trends are accentuated during the last decade and may exert a weakening effect on the westerly zonal flow over our area of interest, being partially responsible of the observed and estimated wind speed trends.

Although there are no visible long-term trends, during the training period a negative trend can be recognized that is statistically significant for the zonal component. This is consistent across different datasets and is partially attributable to changes in the largescale circulation.

\section{Conclusions and discussion}

This work has analyzed the summertime (JJASO) regional to local surface zonal and meridional wind variability over northeastern North America using a statistical downscaling methodology mainly based on EOF and CCA techniques. This methodology has helped identifying the main large- and local-scale coupled circulation modes responsible for the surface wind behavior. The estimated wind obtained from a linear regression based on these modes of circulation has been subjected to a sensitivity analysis focused on five different methodological aspects: predictor variables, size of the predictor domain, retained EOF and CCA modes, cross-validation subset size, and predictor source. This analysis has been conducted using a subset of 95 observational sites (WNENA SD $_{\text {) }}$ and a series of large-scale variables obtained from 12 global reanalyses (whose different contribution to the skill of the downscaled wind has also been analyzed) and two additional SLP observational gridded datasets during the training period 1980-2010. This exercise has allowed us to extrapolate the identified large-to-local relationships beyond the training and also the observational (1953-2010) period, reconstructing the surface wind variability for the 1850-2010 interval with the help of twentiethcentury reanalyses and observational gridded datasets. This section not only draws the main conclusions of this work, but it also discusses them in comparison with the main findings obtained for wintertime in LucioEceiza et al. (2019).

The summertime variability over this region can be explained, to a large extent $(62.5 \%$ for predictand, $51.6 \%$ for predictor), in terms of changes in four modes of circulation, in a reference configuration that used SLP as the sole predictor variable. Due to the location of our region of interest these covariability modes are primarily related to AO/NAO patterns. Surprisingly the leading mode, which is configured by a meridionally leaning dipole, is not particularly related to any of the teleconnection modes that are influential over the Pacific and Atlantic. Each of these modes of circulation explains a similar amount of variance in the reference configuration. Conversely, during wintertime the first mode, defined by a zonally distributed dipole that is very closely related to winter $\mathrm{AO} / \mathrm{NAO}$, clearly dominates over the rest. The estimates obtained from these four coupled circulation modes 
have reasonable correlation values with respect to the observations, especially for the meridional wind component. These correlations are very similar between the different predictor sources. The estimations derived from the reference configuration during winter yielded a similar albeit narrower correlation spread between predictor sources. Also contrary to summer, the zonal winter winds were better characterized than meridional ones.

The sensitivity of the summertime (wintertime) SD estimates is mostly dependent on changes of the number of retained EOF/CCA modes for most of the sites and, to a lesser extent and confined over the northern (center) region of the Gulf of St. Lawrence, on the variable used as predictor (window size). This spatial dependence is more evident for zonal estimations than for meridional ones. The SD proved robust to changes in the cross-validation subset, and it also yields very similar results regardless of the used predictor source, which widely vary in assimilated data, parameterizations used, and horizontal resolutions. The uncertainty of the estimates is larger for sites with larger variability that correspond to places with higher wind speeds. The sensitivity results are in relative terms very similar for both wind components and calendar seasons.

An adequate choice of parameters is able to considerably improve the skill of estimations given by the reference configuration offering high correlation values and a realistic representation of the variance, very similar for the different reanalysis sources. These SD estimates are, in general, more realistic than the ones simulated by the reanalyses in terms of their reproduced variance although their correlation values are slightly lower than those obtained from the reanalyses. Contrary to the SD estimations, there is a notable difference in the variance of the winds from one reanalysis to another. Both summer and winter seasons show qualitatively similar skills of SD estimates and reanalysis simulated winds. Notwithstanding, wintertime SD estimates and reanalysis winds offer slightly better results with respect to the observations than during summertime. As mentioned in the introduction, surface winds are primarily shaped by pressure gradients, which are more intense during winters and weaker in summers. Consequently, the summertime modes of variability explain a smaller variance (as derived from the comparison of the reference configuration for both seasons in section 4), making the wintertime reanalysis and SD estimations slightly more accurate.

A reconstruction of the surface wind variability of the last 160 years has been conducted with the help of twentieth-century-long reanalyses and two additional SLP observational gridded datasets. The reconstructed regional wind anomalies show a similar variance for both meridional and zonal components. The estimates obtained from the 14 different large-scale sources show very similar variability, although some noteworthy inconsistencies have been found during the early decades between ERA-20C/CERA-20C and (1900-20) and HadSLP2r/20CRv2c (1860-80). These inconsistencies are attributable to fewer available data in the past and/ or artificial biases on the assimilated SLP data, whose effect is usually amplified with the increasing data scarcity. During wintertime, although the discrepancy between HadSLP2r and 20CRv2c is also present, the reanalyses show greater agreement for the rest of the analyzed period. A sensitivity analysis similar to that conducted during the training period shows that the uncertainty band remains more or less constant during both seasons, except for periods with wider uncertainties corresponding to the discrepancies discussed before. This reconstruction has permitted to capture the variability at longer time scales (interdecadal) than those identified during the training period (interannual). There are no overall significant long-term trends at multidecadal time scales. However, during summer there are statistically significant negative trends shown by the observations, some SD estimations, and the majority of reanalyses that affect the regional zonal wind component for the last three decades (1980-2010) and that are not observed for winter. Although these trends do not stand out in the multidecadal context, they are still noteworthy as they are consistent in magnitude and sign with findings related to a global-scale stilling process identified during the last decades, which in this case can be partially attributable to changes in the large-scale dynamics.

Acknowledgments. This research has been conducted under the Joint Research Unit between UCM and CIEMAT, by the Collaboration Agreement 7158/2016. Part of the financial support for some of the authors involved in this work was provided by the Agreement of Cooperation 4164281 (funded by the Natural Sciences and Engineering Research Council of Canada NSERC DG 140576948, the Canada Research Chairs Program CRC 230687, and the Atlantic Innovation Fund AIF-ACOA) between the UCM and St. Francis Xavier University, the ILMODELS (CGL2014-59644-R), NEWA (PCIN-2014-017-C07-03, PCIN-2014-017-C07-06) and NEWA2 (PCIN-2016-176, PCIN-2016-009) projects of MINECO (Spain), and GLOBAL Forecasters S.L. Special thanks to Douglas Schuster for information regarding the assimilation of surface wind land observations in NCAR-R1, DOE-R2 and CFSR reanalyses. Note: a version of the observational data used in this study will be made public. Likewise, the wind climatologies showed in the manuscript will also be available. 
Potential users interested in having the data are invited to contact the corresponding author.

\section{REFERENCES}

Allan, R., and T. Ansell, 2006: A new globally complete monthly historical gridded mean sea level pressure dataset (HadSLP2): 1850 2004. J. Climate, 19, 5816-5842, https://doi.org/10.1175/JCLI3937.1.

Atkinson, B. W., 1981: Mesoscale Atmospheric Circulation. Academic Press, 495 pp.

Azorin-Molina, C., and Coauthors, 2014: Homogenization and assessment of observed near-surface wind speed trends over Spain and Portugal, 1961-2011. J. Climate, 27, 3692-3712, https://doi.org/10.1175/JCLI-D-13-00652.1.

- , S. M. Vicente-Serrano, T. R. McVicar, J. Revuelto, S. Jerez, and J. I. López-Moreno, 2017: Assessing the impact of measurement time interval when calculating wind speed means and trends under the stilling phenomenon. Int. J. Climatol., 37, 480-492, https://doi.org/10.1002/joc.4720.

Barnston, A. G., and R. E. Livezey, 1987: Classification, seasonality and persistence of low-frequency atmospheric circulation patterns. Mon. Wea. Rev., 115, 1083-1126, https://doi.org/ 10.1175/1520-0493(1987)115<1083:CSAPOL > 2.0.CO;2.

Befort, D. J., S. Wild, T. Kruschke, U. Ulbrich, and G. C. Leckebusch, 2016: Different long-term trends of extra-tropical cyclones and windstorms in ERA-20C and NOAA-20CR reanalyses. Atmos. Sci. Lett., 17, 586-595, https://doi.org/10.1002/ asl.694.

Bianco, L., B. Tomassetti, E. Coppola, A. Fracassi, M. Verdecchia, and G. Visconti, 2006: Thermally driven circulation in a region of complex topography: Comparison of wind-profiling radar measurements and MM5 numerical predictions. Ann. Geophys., 24, 1537-1549, https://doi.org/10.5194/angeo-24-1537-2006.

Brinckmann, S., S. Krähenmann, and P. Bissolli, 2016: High-resolution daily gridded data sets of air temperature and wind speed for Europe. Earth Syst. Sci. Data, 8, 491-516, https://doi.org/10.5194/ essd-8-491-2016.

Cane, M. A., 1986: El Niño. Ann. Rev. Earth Planet. Sci., 14, 43-70, https://doi.org/10.1146/annurev.ea.14.050186.000355.

Cheng, C. S., 2014: Evidence from the historical record to support projection of future wind regimes: An application to Canada. Atmos.Ocean, 52, 232-241, https://doi.org/10.1080/07055900.2014.902803.

CISL RDA, 1979: Daily Northern Hemisphere sea level pressure grids, continuing from 1899. Research Data Archive at the National Center for Atmospheric Research, Computational and Information Systems Laboratory, accessed 6 May 2015, http://rda.ucar.edu/datasets/ds010.0/.

CRIEPI and JMA, 2007: Japanese 25-year Reanalysis Project. Research Data Archive at the National Center for Atmospheric Research, Computational and Information Systems Laboratory, accessed 22 May 2015, http://rda.ucar.edu/datasets/ds625.0/. 2008: Japanese 25-year Reanalysis Project, monthly means. Research Data Archive at the National Center for Atmospheric Research, Computational and Information Systems Laboratory, accessed 24 May 2015, http://rda.ucar.edu/datasets/ds625.1/.

Compo, G. P., and Coauthors, 2011: The Twentieth Century Reanalysis Project. Quart. J. Roy. Meteor. Soc., 137, 1-28, https://doi.org/10.1002/qj.776.

, and Coauthors, 2015: NOAA/CIRES Twentieth Century Global Reanalysis Version 2c. Updated yearly, Research Data Archive at the National Center for Atmospheric Research,
Computational and Information Systems Laboratory, accessed 4 June 2015, https://doi.org/10.5065/D6N877TW.

Conrad, C. T., 2009: Severe and Hazardous Weather in Canada: The Geography of Extreme Events. Oxford University Press, $45-53$

Correia, J., A. Bastos, M. Brito, and R. Trigo, 2017: The influence of the main large-scale circulation patterns on wind power production in Portugal. Renew. Energy, 102, 214-223, https:// doi.org/10.1016/j.renene.2016.10.002.

Cram, T. A., and Coauthors, 2015: The International Surface Pressure Databank version 2. Geosci. Data J., 2, 31-46, https:// doi.org/10.1002/gdj3.25.

Culver, A. M. R., and A. H. Monahan, 2013: The statistical predictability of surface winds over western and central Canada. J. Climate, 26, 8305-8322, https://doi.org/10.1175/JCLI-D-1200425.1

Dee, D., and Coauthors, 2011: The ERA-Interim reanalysis: Configuration and performance of the data assimilation system. Quart. J. Roy. Meteor. Soc., 137, 553-597, https://doi.org/ 10.1002/qj.828.

Ebita, A., and Coauthors, 2011: The Japanese 55-year Reanalysis "JRA-55": An interim report. SOLA, 7, 149-152, https:// doi.org/10.2151/sola.2011-038.

Farquhar, G., and M. Roderick, 2005: Worldwide changes in evaporative demand. Water and the Environment, Scripta Varia 108 Vatican City, Pontifical Academy of Sciences, 81-103, http:// www.pas.va/content/dam/accademia/pdf/sv108/sv108-farquhar.pdf.

Ferguson, C. R., and G. Villarini, 2014: An evaluation of the statistical homogeneity of the Twentieth Century Reanalysis. Climate Dyn., 42, 2841-2866, https://doi.org/10.1007/s00382 013-1996-1.

Fowler, H., S. Blenkinsop, and C. Tebaldi, 2007: Linking climate change modelling to impacts studies: Recent advances in downscaling techniques for hydrological modelling. Int. J. Climatol., 27, 15471578, https://doi.org/10.1002/joc.1556.

García-Bustamante, E., J. F. González-Rouco, J. Navarro, E. Xoplaki, P. a. Jiménez, and J. P. Montávez, 2012: North Atlantic atmospheric circulation and surface wind in the Northeast of the Iberian Peninsula: Uncertainty and long term downscaled variability. Climate Dyn., 38, 141-160, https://doi.org/10.1007/s00382-0100969-x.

and Coauthors, 2013: Relationship between wind power production and North Atlantic atmospheric circulation over the northeastern Iberian Peninsula. Climate Dyn., 40, 935-949, https://doi.org/10.1007/s00382-012-1451-8.

González-Rouco, J. F., H. Heyen, E. Zorita, and F. Valero, 2000 Agreement between observed rainfall trends and climate change simulations in the southwest of Europe. J. Climate, $\mathbf{1 3}$ 3057-3065, https://doi.org/10.1175/1520-0442(2000)013<3057: ABORTA $>2.0 . \mathrm{CO} ; 2$.

Hart, R. E., and J. L. Evans, 2001: A climatology of the extratropical transition of Atlantic tropical cyclones. J. Climate, 14, 546-564, https://doi.org/10.1175/1520-0442(2001)014<0546: ACOTET $>2.0 . \mathrm{CO} ; 2$.

Hartmann, D. J., and Coauthors, 2013: Observations: Atmosphere and surface. Climate Change 2013: The Physical Science Basis, T. F. Stocker et al., Eds., Cambridge University Press, 159254.

Hersbach, H., P. Poli, and D. Dee, 2015: The observation feedback archive for the ICOADS and ISPD data sets (ERA-20C) ERA Rep. Series 18, ECMWF, 31 pp., https://www.ecmwf.int/ node/9871. 
Hertig, E., A. Paxian, G. Vogt, S. Seubert, H. Paeth, and J. Jacobeit, 2012: Statistical and dynamical downscaling assessments of precipitation extremes in the Mediterranean area. Meteor. Z., 21, 61-77, https://doi.org/10.1127/0941-2948/2012/0271.

Hurrell, J. W., 1995: Decadal trends in the North Atlantic Oscillation: Regional temperatures and precipitation. Science, 269, 676-679, https://doi.org/10.1126/science.269.5224.676.

Huth, R., 2002: Statistical downscaling of daily temperature in central Europe. J. Climate, 15, 1731-1742, https://doi.org/ 10.1175/1520-0442(2002)015<1731:SDODTI >2.0.CO;2.

Jiménez, P. A., J. F. González-Rouco, J. P. Montávez, and E. García-Bustamante, 2008: Climatology of wind patterns in the northeast of the Iberian Peninsula. Int. J. Climatol., https:// doi.org/10.1002/joc.1705.

JMA, 2013: JRA-55: Japanese 55-year Reanalysis, monthly means and variances. Research Data Archive at the National Center for Atmospheric Research, Computational and Information Systems Laboratory, accessed 23 April 2015, https://doi.org/ 10.5065/D60G3H5B.

Kaas, E., T.-S. Li, and T. Schmith, 1996: Statistical hindcast of wind climatology in the North Atlantic and northwestern European region. Climate Res. 7, 97-110, https://doi.org/10.3354/cr007097.

Kalnay, E., and Coauthors, 1996: The NCEP/NCAR 40-Year Reanalysis Project. Bull. Amer. Meteor. Soc., 77, 437-471, https:// doi.org/10.1175/1520-0477(1996)077<0437:TNYRP>2.0.CO;2.

Kanamitsu, M., W. Ebisuzaki, J. Woollen, S. K. Yang, J. J. Hnilo, M. Fiorino, and G. L. Potter, 2002: NCEP-DOE AMIP-II reanalysis (R-2). Bull. Amer. Meteor. Soc., 83, 1631-1643, https://doi.org/10.1175/BAMS-83-11-1631.

Khanduri, A., and G. Morrow, 2003: Vulnerability of buildings to windstorms and insurance loss estimation. J. Wind Eng. Ind. Aerodyn., 91, 455-467, https://doi.org/10.1016/S0167-6105(02) 00408-7.

Klink, K., 1999: Climatological mean and interannual variance of United States surface wind speed, direction and velocity. Int. J. Climatol., 19, 471-488, https://doi.org/10.1002/(SICI)10970088(199904)19:5<471::AID-JOC367>3.0.CO;2-X.

Kobayashi, C., H. Endo, Y. Ota, S. Kobayashi, H. Onoda, Y. Harada, K. Onogi, and H. Kamahori, 2014: Preliminary results of the JRA-55C, an atmospheric reanalysis assimilating conventional observations only. SOLA, 10, 78-82, https:// doi.org/10.2151/sola.2014-016.

Laloyaux, P., M. Balmaseda, D. Dee, K. Mogensen, and P. Janssen, 2016: A coupled data assimilation system for climate reanalysis. Quart. J. Roy. Meteor. Soc., 142, 65-78, https://doi.org/10.1002/qj.2629.

Lorenz, E. N., 1956: Empirical orthogonal functions and statistical weather prediction. Sci. Rep. 1, Dept. of Meteorology, Massachusetts Institute of Technology, $52 \mathrm{pp}$.

Lucio-Eceiza, E. E., J. F. González-Rouco, J. Navarro, and H. Beltrami, 2018a: Quality Control of surface wind observations in northeastern North America. Part I: Data management issues. J. Atmos. Oceanic Technol., 35, 163-182, https://doi.org/ 10.1175/JTECH-D-16-0204.1.

,,,,---- and J. Conte, 2018b: Quality control of surface wind observations in northeastern North America. Part II: Measurement errors. J. Atmos. Oceanic Technol., 35, 183-205, https://doi.org/10.1175/JTECH-D-16-0205.1.

E. García-Bustamante, J. Navarro, and H. Beltrami, 2019: Multidecadal to centennial surface wintertime wind variability over northeastern North America via statistical downscaling. Climate Dyn., 53, 41-66, https://doi.org/10.1007/s00382-018-4569-5.

Mantua, N. J., S. R. Hare, Y. Zhang, J. M. Wallace, and R. C. Francis, 1997: A Pacific interdecadal climate oscillation with impacts on salmon production. Bull. Amer. Meteor. Soc., 78, 1069-1079, https://doi.org/10.1175/1520-0477(1997)078<1069: APICOW $>2.0 . \mathrm{CO} ; 2$.

Martinez, Y., W. Yu, and H. Lin, 2013: A new statistical-dynamical downscaling procedure based on EOF analysis for regional time series generation. J. Appl. Meteor. Climatol., 52, 935-952, https://doi.org/10.1175/JAMC-D-11-065.1.

McVicar, T. R., T. G. Van Niel, L. T. Li, M. L. Roderick, D. P. Rayner, L. Ricciardulli, and R. J. Donohue, 2008: Wind speed climatology and trends for Australia, 1975-2006: Capturing the stilling phenomenon and comparison with near-surface reanalysis output. Geophys. Res. Lett., 35, L20403, https://doi.org/10.1029/2008GL035627.

- and Coauthors, 2012: Global review and synthesis of trends in observed terrestrial near-surface wind speeds: Implications for evaporation. J. Hydrol., 416-417, 182-205, https://doi.org/ 10.1016/j.jhydrol.2011.10.024.

Monahan, A. H., 2012: Can we see the wind? Statistical downscaling of historical sea surface winds in the subarctic northeast Pacific. J. Climate, 25, 1511-1528, https://doi.org/10.1175/2011JCLI4089.1.

MRI/JMA, 2015: JRA-55C: Monthly means and variances. Research Data Archive at the National Center for Atmospheric Research, Computational and Information Systems Laboratory, accessed 10 May 2017, https://doi.org/10.5065/D6C827B7.

Murthy, K. S., and O. P. Rahi, 2017: A comprehensive review of wind resource assessment. Renewable Sustainable Energy Rev., 72, 1320-1342, https://doi.org/10.1016/j.rser.2016.10.038.

Najac, J., J. Boé, and L. Terray, 2009: A multi-model ensemble approach for assessment of climate change impact on surface winds in France. Climate Dyn., 32, 615-634, https://doi.org/ 10.1007/s00382-008-0440-4.

National Center for Atmospheric Research, 2016: The Climate Data Guide: Hurrell North Atlantic Oscillation (NAO) Index (PCbased). NCAR, https://climatedataguide.ucar.edu/climate-data/ hurrell-north-atlantic-oscillation-nao-index-pc-based.

North, G. R., F. J. Moeng, T. L. Bell, R. F. Cahalan, F. J. Moeng, T. L. Bell, and R. F. Cahalan, 1982: The latitude dependence of the variance of zonally averaged quantities. Mon. Wea. Rev., 110, 319-326, https://doi.org/10.1175/1520-0493(1982) $110<0319$ :TLDOTV $>2.0$. CO 2 .

Onogi, K., and Coauthors, 2007: The JRA-25 Reanalysis. J. Meteor. Soc. Japan, 85, 369-432, https://doi.org/10.2151/jmsj.85.369.

Pearson, K., 1901: On lines and planes of closest fit to systems of points in space. London Edinburgh Dublin Philos. Mag. J. Sci., 2, 559-572, https://doi.org/10.1080/14786440109462720.

Peixoto, J. P., and A. H. Oort, 1992: Physics of Climate. Springer, $520 \mathrm{pp}$.

Phillips, D., 1990: The Climates of Canada. Environment Canada, $176 \mathrm{pp}$.

Poli, P., and Coauthors, 2016: ERA-20C: An atmospheric reanalysis of the twentieth century. J. Climate, 29, 4083-4097, https://doi.org/10.1175/JCLI-D-15-0556.1.

Pryor, S. C., J. T. Schoof, and R. J. Barthelmie, 2006: Winds of change?: Projections of near-surface winds under climate change scenarios. Geophys. Res. Lett., 33, L11702, https:// doi.org/10.1029/2006GL026000.

and Coauthors, 2009: Wind speed trends over the contiguous United States. J. Geophys. Res., 114, D14105, https://doi.org/ 10.1029/2008JD011416.

, R. J. Barthelmie, N. E. Clause, M. Drews, N.MacKellar, and E. Kjellström, 2012a: Analyses of possible changes in intense and extreme wind speeds over northern Europe under climate change scenarios. Climate Dyn., 38, 189-208, https://doi.org/ 10.1007/s00382-010-0955-3. 
$\longrightarrow,-$, and J. T. Schoof, 2012b: Past and future wind climates over the contiguous USA based on the North American Regional Climate Change Assessment Program model suite. J. Geophys. Res., 117, D19119, https://doi.org/10.1029/2012JD017449.

Rasmusson, E. M., and J. M. Wallace, 1983: Meteorological aspects of the El Niño/Southern Oscillation. Science, 222, 1195-1202, https://doi.org/10.1126/science.222.4629.1195.

Richards, W., and Y. Abuamer, 2007: Atmospheric hazards: Extreme wind gust climatology in Atlantic Canada 1955-2000. Meteorological Service of Canada Science Report Series EN57-36/2007-1E-PDF, 47 pp.

Rienecker, M. M., and Coauthors, 2011: MERRA: NASA's Modern-Era Retrospective Analysis for Research and Applications. J. Climate, 24, 3624-3648, https://doi.org/10.1175/JCLI-D-11-00015.1.

Ropelewski, C. F., and P. D. Jones, 1987: An extension of the Tahiti-Darwin Southern Oscillation Index. Mon. Wea. Rev., 115, 2161-2165, https://doi.org/10.1175/1520-0493(1987) $115<2161$ :AEOTTS $>2.0$.CO;2.

Saha, S., and Coauthors, 2010a: The NCEP Climate Forecast System Reanalysis. Bull. Amer. Meteor. Soc., 91, 1015-1057, https://doi.org/10.1175/2010BAMS3001.1.

—_, and Coauthors, 2010b: NCEP Climate Forecast System Reanalysis (CFSR) monthly products, January 1979 to December 2010. Research Data Archive at the National Center for Atmospheric Research, Computational and Information Systems Laboratory, accessed 25 May 2015, https:// doi.org/10.5065/D6DN438J.

Sharp, E., P. Dodds, M. Barrett, and C. Spataru, 2015: Renew. Energy, 77, 527-538, https://doi.org/10.1016/j.renene.2014.12.025.

Smits, A., A. M. Klein Tank, and G. P. Können, 2005: Trends in storminess over the Netherlands, 1962-2002. Int. J. Climatol., 25, 1331-1344, https://doi.org/10.1002/joc.1195.

Taylor, K. E., 2001: Summarizing multiple aspects of model performance in a single diagram. J. Geophys. Res., 106, 71837192, https://doi.org/10.1029/2000JD900719.

Themeß1, M. J., A. Gobiet, and A. Leuprecht, 2011: Empirical-statistical downscaling and error correction of daily precipitation from regional climate models. Int. J. Climatol., 31, 1530-1544, https://doi.org/10.1002/joc.2168.

Thompson, D. W. J., and J. M. Wallace, 1998: The Arctic oscillation signature in the wintertime geopotential height and temperature fields. Geophys. Res. Lett., 25, 1297, https://doi.org/10.1029/98GL00950.

, and _ 2000a: Annular modes in the extratropical circulation. Part I: Month-to-month variability. J. Climate, 13, 1000-1016, https://doi.org/10.1175/1520-0442(2000)013<1000: AMITEC $>2.0 . \mathrm{CO} ; 2$.

$\longrightarrow$, and $\_$2000b: Annular modes in the extratropical circulation. Part II: Trends. J. Climate, 13, 1018-1036, https://doi.org/ 10.1175/1520-0442(2000)013<1018:AMITEC > 2.0.CO;2.

Torralba, V., F. J. Doblas-Reyes, D. MacLeod, I. Christel, and M. Davis, 2017: Seasonal climate prediction: A new source of information for the management of wind energy resources. J. Appl. Meteor. Climatol., 56, 1231-1247, https://doi.org/ 10.1175/JAMC-D-16-0204.1.

Torrence, C., and G. P. Compo, 1998: A practical guide to wavelet analysis. Bull. Amer. Meteor. Soc., 79, 61-78, https://doi.org/10.1175/15200477(1998)079<0061:APGTWA > 2.0.CO;2.

Trenberth, K. E., 1984: Signal versus noise in the Southern Oscillation. Mon. Wea. Rev., 112, 326-332, https://doi.org/ 10.1175/1520-0493(1984)112<0326:svnits >2.0.co;2.

— tions in the Pacific. Climate Dyn., 9, 303-319, https://doi.org/ 10.1007/BF00204745.
Troen, I., and E. L. Petersen, 1989: European Wind Atlas. Ris $\varnothing$ National Laboratory, $656 \mathrm{pp}$.

Tuller, S. E., 2004: Measured wind speed trends on the west coast of Canada. Int. J. Climatol., 24, 1359-1374, https://doi.org/10.1002/ joc.1073.

Uppala, S. M., and Coauthors, 2005: The ERA-40 Re-Analysis. Quart. J. Roy. Meteor. Soc., 131, 2961-3012, https://doi.org/ 10.1256/qj.04.176.

van der Kamp, D., C. L. Curry, and A. H. Monahan, 2012: Statistical downscaling of historical monthly mean winds over a coastal region of complex terrain. II. Predicting wind components. Climate Dyn., 38, 1301-1311, https://doi.org/ 10.1007/s00382-011-1175-1.

Vautard, R., J. Cattiaux, P. Yiou, J.-N. Thépaut, and P. Ciais, 2010: Northern Hemisphere atmospheric stilling partly attributed to an increase in surface roughness. Nat. Geosci., 3, 756-761, https://doi.org/10.1038/ngeo979.

von Storch, H., E. Zorita, and U. Cubasch, 1993: Downscaling of global climate change estimates to regional scales: An application to Iberian rainfall in wintertime. J. Climate, 6 , 1161-1171, https://doi.org/10.1175/1520-0442(1993)006<1161: DOGCCE $>2.0 . \mathrm{CO} ; 2$.

Wan, H., X. L. Wang, and V. R. Swail, 2010: Homogenization and trend analysis of Canadian near-surface wind speeds. J. Climate, 23, 1209, https://doi.org/10.1175/2009JCLI3200.1.

Wang, X. L., H. Wan, and V. R. Swail, 2006: Observed changes in cyclone activity in Canada and their relationships to major circulation regimes. J. Climate, 19, 896-915, https://doi.org/10.1175/JCLI3664.1. , Y. Feng, G. P. Compo, V. R. Swail, F. W. Zwiers, R. J. Allan, and P. D. Sardeshmukh, 2013: Trends and low frequency variability of extra-tropical cyclone activity in the ensemble of twentieth century reanalysis. Climate Dyn., 40, 2775-2800, https://doi.org/10.1007/s00382-012-1450-9.

WMO, 2011: Guide to climatological practices. WMO-100,117 pp., https://library.wmo.int/doc_num.php?explnum_id $=5541$.

Wójcik, R., 2015: Reliability of CMIP5 GCM simulations in reproducing atmospheric circulation over Europe and the North Atlantic: A statistical downscaling perspective. Int. J. Climatol., 35, 714-732, https://doi.org/10.1002/joc.4015.

Wu, J., J. Zha, and D. Zhao, 2017: Evaluating the effects of land use and cover change on the decrease of surface wind speed over China in recent 30 years using a statistical downscaling method. Climate Dyn., 48, 131-149, https://doi.org/10.1007/s00382-0163065-z.

Xoplaki, E., J. F. González-Rouco, J. Luterbacher, and H. Wanner, 2003: Mediterranean summer air temperature variability and its connection to the large-scale atmospheric circulation and SSTs. Climate Dyn., 20, 723-739, https://doi.org/10.1007/s00382003-0304-x.

,,--- , and -2004 : Wet season Mediterranean precipitation variability: Influence of large-scale dynamics and trends. Climate Dyn., 23, 63-78, https://doi.org/10.1007/s00382-004-0422-0.

Yan, Z., S. Bate, R. E. Chandler, V. Isham, and H. Wheater, 2002: An analysis of daily maximum wind speed in northwestern Europe using generalized linear models. J. Climate, 15, 2073-2088, https:// doi.org/10.1175/1520-0442(2002)015<2073:AAODMW>2.0.CO;2.

Zhang, Y., J. M. Wallace, and D. S. Battisti, 1997: ENSO-like interdecadal variability: 1900-93. J. Climate, 10, 1004-1020, https:// doi.org/10.1175/1520-0442(1997)010<1004:ELIV>2.0.CO;2.

Zorita, E., and H. von Storch, 1999: The analog method as a simple statistical downscaling technique: Comparison with more complicated methods. J. Climate, 12, 2474-2489, https://doi.org/ 10.1175/1520-0442(1999)012<2474:TAMAAS>2.0.CO;2. 